\title{
Ornithine capture by a translating ribosome controls bacterial polyamine synthesis
}

\author{
Alba Herrero del Valle ${ }^{1 *}$, Britta Seip $\uparrow^{1}{ }^{*}$, Iñaki Cervera-Marzal ${ }^{1} \dagger$, Guénaël Sacheau ${ }^{1} \dagger$, A. Carolin \\ Seefeldt ${ }^{1} \uparrow \&$ C. Axel Innis ${ }^{1}$ \\ ${ }^{1}$ Institut Européen de Chimie et Biologie, Univ. Bordeaux, Institut National de la Santé et de la Recherche Médicale \\ (U1212) and Centre National de la Recherche Scientifique (UMR 5320), Pessac 33607, France. † Present addresses: \\ Evotec International GmbH, Marie-Curie-Straße, 37079 Göttingen, Germany (B.S.); Aix Marseille Univ., CNRS, \\ INSERM, CIML, Centre d'Immunologie de Marseille-Luminy, Marseille, France. (I.C.-M.); Sopra Steria, Armor Plaza, \\ 5-7 Impasse Claude Nougaro, 44800 Saint-Herblain, France (G.S.); Department of Cell and Molecular Biology, \\ Biomedical Center, Uppsala University, Box 596, 75124 Uppsala, Sweden (A.C.S.).
}

* These authors contributed equally to this work

\begin{abstract}
Polyamines are essential metabolites that play an important role in cell growth, stress adaptation, and microbial virulence ${ }^{1-3}$. In order to survive and multiply within a human host, pathogenic bacteria adjust the expression and activity of polyamine biosynthetic enzymes in response to different environmental stresses and metabolic cues ${ }^{2}$. Here, we show that ornithine capture by the ribosome and the nascent peptide SpeFL controls polyamine synthesis in $\gamma$-proteobacteria by inducing the expression of the ornithine decarboxylase SpeF $^{4}$, via a mechanism involving ribosome stalling and transcription antitermination. In addition, we present the cryo-EM structure of an Escherichia coli $(E$. coli) ribosome stalled during translation of $s p e F L$ in the presence of ornithine. The structure shows how the ribosome and the SpeFL sensor domain form a highly selective binding pocket that accommodates a single ornithine molecule but excludes near-cognate ligands. Ornithine pre-associates with the ribosome and is then held in place by the sensor domain, leading to the compaction of the SpeFL effector domain and blocking the action of release factor RF1. Thus, our study not only reveals basic strategies by which nascent peptides assist the ribosome in detecting a specific metabolite, but also provides a framework for assessing how ornithine promotes virulence in several human pathogens.
\end{abstract}




\section{INTRODUCTION}

Putrescine is a naturally abundant polyamine that is produced from ornithine by the enzyme ornithine decarboxylase, whose expression and activity are tightly regulated ${ }^{2}$. Two ornithine decarboxylase genes exist in $E$. coli, the constitutive speC and the inducible spe $F$, which along with its operon partner pot $E$, an ornithine-putrescine antiporter, is expressed under mild acidic stress and high ornithine levels $\mathrm{s}^{4-6}$. Searching for regulatory elements upstream of spe $F$, we found a short open reading frame (ORF) encoding a putative 34 -amino acid peptide, which we named speFL (leader of speF) (see Methods, Fig. 1a). This ORF is conserved in many pathogenic $\gamma$-proteobacteria (Supplementary Fig. 1), including Salmonella Typhimurium (S. Typhimurium), where it was recently reported as orf34 $4^{7}$. Translation of orf34 in the presence of ornithine activates spe $F$ expression by preventing premature Rho-dependent transcription termination ${ }^{7}$. However, the mechanism by which ornithine triggers speF expression is unknown.

\section{RESULTS}

To investigate how speF is activated, we performed toeprinting assays ${ }^{8,9}$ to monitor the position of ribosomes on a transcript encoding SpeFL (Fig. $1 \mathrm{~b}$ and Supplementary Data 1, Supplementary Tables 1 and 2). A faint toeprint corresponding to ribosomes that reached the UAG stop codon was visible in the absence of exogenous ligand. Addition of ornithine resulted in two strong toeprint signals for ribosomes stalled with codons 33 or 34 of speFL in the ribosomal P-site. Ribosome stalling occurred in a dose-dependent manner with respect to ornithine concentration (Supplementary Fig. 2), but no toeprints were observed in the presence of putrescine, highlighting the strict dependence of the stalling process on ornithine availability. Translating a double-frameshifted $s p e F L_{f s}$ template that encodes a different amino acid sequence did not yield ornithine-dependent toeprints (Supplementary Fig. 3), indicating that ribosome stalling depends on the nascent peptide rather than on the mRNA structure. In the absence of release factors, the toeprint at position 34 intensified, reflecting impaired translation termination. Treatment with puromycin led to the disappearance of this toeprint, while ornithine-dependent toeprints remained visible. Puromycin causes premature peptide release and insensitivity to this antibiotic is characteristic of arrest peptides, a class of nascent regulatory peptides that stall the ribosomes that are translating them, often in a liganddependent manner ${ }^{10,11}$. Finally, we showed that an RNA element including speFL and the 257nucleotide spe $F L$-spe $F$ intergenic region induces the expression of a spe $F_{1-3}-l a c Z \alpha$ translational fusion in vivo in response to ornithine (Fig. 1c). Treatment with bicyclomycin, which specifically blocks the ATPase activity of $\mathrm{Rho}^{12}$, resulted in constitutive $s_{p e} F_{1-3}$-lacZ $\alpha$ expression, confirming the previously reported ${ }^{7}$ involvement of Rho in the regulation of spe $F$. Thus, ribosomes translating speFL stall in an ornithine-dependent manner, inducing spe $F$ through a Rho-dependent mechanism.

In S. Typhimurium, Rho-dependent transcription termination occurs immediately downstream of an mRNA hairpin that includes the $3^{\prime}$ end of speFL'. This hairpin is conserved in $E$. coli and would cause an RNA polymerase that has just finished transcribing speFL to pause (Fig. $1 \mathrm{~d}$, Supplementary Fig. 4). A ribosome translating speFL can unwind the pause hairpin upon reaching the stop codon, freeing the RNA polymerase and allowing transcription to resume. When ornithine levels are low, the leading ribosome on speFL terminates and dissociates from the mRNA, exposing part of a predicted Rho utilization (rut) site $^{13}$. Rho-mediated transcriptional attenuation is commonly used for metabolic control and can be coupled with translational arrest at a leader ORF, for example during the regulation of $E$. coli tryptophanase operon by the tryptophan-dependent arrest peptide $\mathrm{TnaC}^{14}$. For Rho to bind to the nascent transcript and cause premature transcription termination, a full rut site must be available. Since polysome accumulation on $s p e F L$ would interfere with rut availability, we hypothesized that consecutive 
rare arginine codons at positions 12 and 13 of speFL may slow translation enough to fully expose the rut site and give Rho a chance to bind. As reported previously ${ }^{7}$, this region of speFL contains rare codons in many $\gamma$-proteobacteria, especially at position 12 (Fig. 1e). While replacing codon 13 with a common synonymous codon caused a mild decrease in $\mathrm{spe}_{1-3^{-}}$ lac $Z \alpha$ induction, the same mutation at position 12 or mutation of both codons gave rise to a basal level of speF expression that was not observed with wild-type speFL (Fig. 1f), consistent with a model whereby efficient Rho binding is dependent on polysomes not accumulating on rut. When ornithine levels are high, the leading ribosome on speFL undergoes nascent peptidemediated translational arrest. Ribosome stalling masks the rut site and polysomes accumulate (Supplementary Fig. 5). This prevents Rho from binding, allowing transcription to proceed and speF to be expressed.
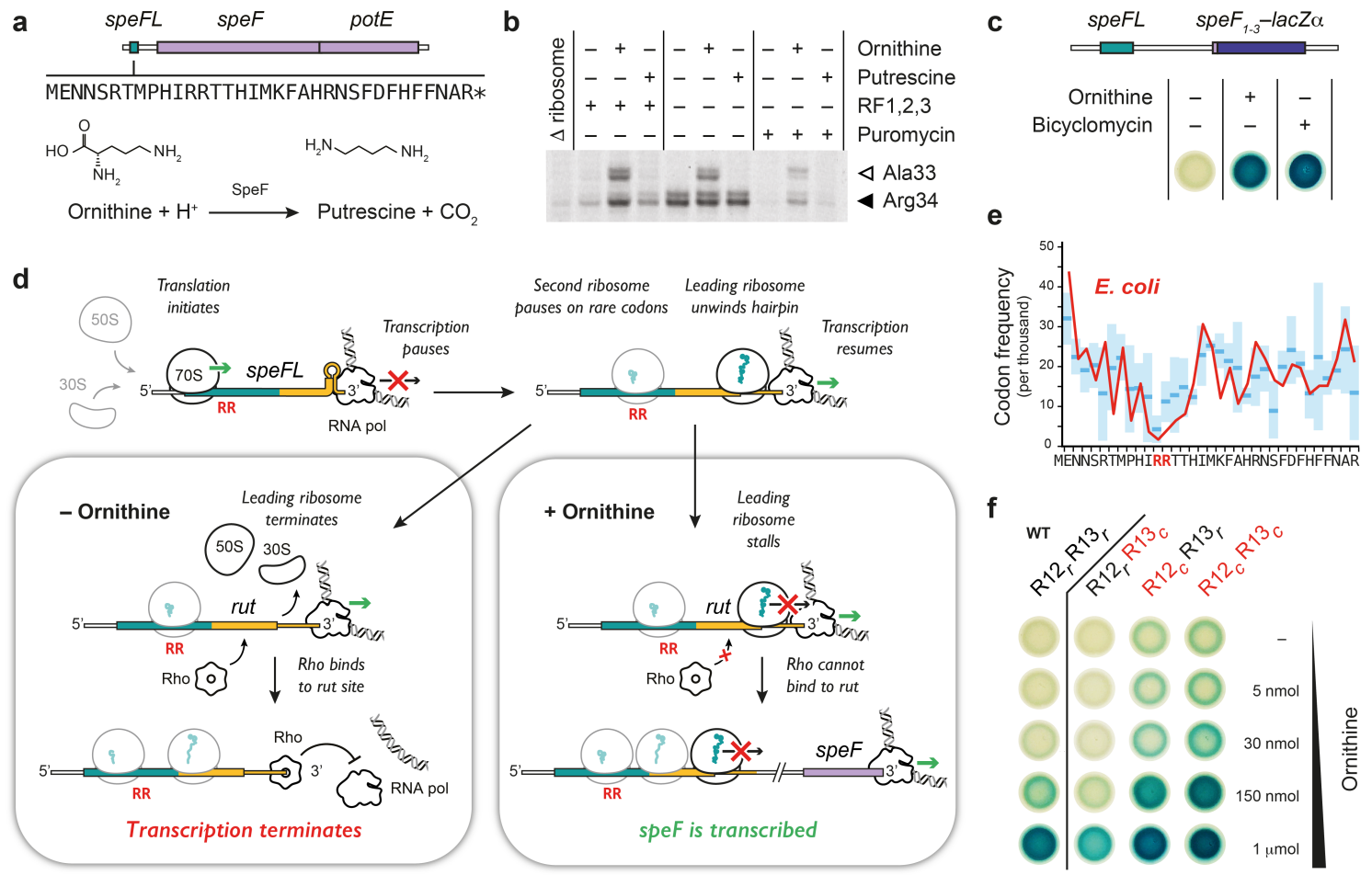

Figure 1 | Mechanism of speF activation by SpeFL and ornithine. a, Schematic layout of the speF operon showing the sequence of the SpeFL peptide and the reaction catalyzed by SpeF. b. Toeprinting assay ${ }^{8,9}$ to monitor the translation of spe $F L$ in the absence (-) or presence (+) of $10 \mathrm{mM}$ ornithine, $10 \mathrm{mM}$ putrescine, release factors (RF1,2,3) or $90 \mu \mathrm{M}$ puromycin. Arrows indicate ribosomes stalled with the codon for the indicated amino acid in the P-site (Ala33 open triangle; Arg34 - filled triangle). c, E. coli TB1 cells ${ }^{56}$ transformed with a plasmid carrying a $\operatorname{spe}_{1-3}-\mathrm{lac} Z \alpha$ translational fusion whose expression is placed under the control of spe $F L$ and the speFL-spe $F$ intergenic region. Cells were grown on rich medium supplemented with $50 \mu \mathrm{g} / \mathrm{ml}$ streptomycin, $100 \mu \mathrm{g} / \mathrm{ml}$ ampicillin, $1 \mathrm{mM} \mathrm{IPTG}$ and $0.5 \mathrm{mM} \mathrm{X-Gal} \mathrm{in} \mathrm{the}$ absence (-) or presence (+) of $3 \mu \mathrm{mol}$ ornithine or $20 \mu \mathrm{g}$ bicyclomycin. Blue cells express the spe $_{1-3}-l a c Z \alpha$ translational fusion. d, Model of speF induction following the ornithinedependent stalling of ribosomes translating speFL. The spe $F L$ open reading frame is boxed and shown partly in turquoise, with the overlapping rut site in yellow. Consecutive rare arginine codons R12 and R13 are shown in red letters. The leading ribosome on speFL is outlined in black while the second and third ribosomes are outlined in gray. The SpeFL peptide is in turquoise. e, Codon frequency at each position of $s p e F L$ in E. coli (red line) and in the Enterobacteriales order $\left(n_{\text {species }}=10\right.$ (see Supplementary Fig. 1 ); mean - blue lines; \pm standard deviation (SD) - light blue boxes). Codon usage values were obtained from the Codon Usage Database (NCBI-Genbank Flat File Release 160.0 [June 15 2007]) ${ }^{57}$. f, The same assay as in C, 
showing the induction of a spe $F_{1-3}-l a c Z \alpha$ translational fusion by wild-type (WT - R12,R13, or synonymous spe $L L$ variants with different combinations of rare $(r)$ or common $(c)$ arginine codons at positions 12 and 13, in the absence $(-)$ or presence $(+)$ of different amounts of ornithine. Mutated codons are shown in red.

To determine how nascent SpeFL functions as an ornithine sensor, we used cryo-EM to obtain two structures of a SpeFL-70S ribosome complex stalled in the presence of ornithine at an overall resolution of $2.7 \AA$ (Fig. 2a, Supplementary Fig. 5, 6 and 7, and Supplementary Table 3). We observed a major subpopulation corresponding to a stalled termination complex with wellresolved density for a 34-residue peptidyl-tRNA ${ }^{\mathrm{Arg}}$ bound to the P-site, but the elongation complex stalled on codon 33 that was seen by toeprinting was not observed (Fig. 2b). This discrepancy may result from differences in the kinetics of the purified translation system used for toeprinting and the S30 extract-based translation system used for cryo-EM sample preparation. Alternatively, the elongation complex may be less stable than the termination complex, resulting in complex dissociation during sucrose gradient centrifugation.
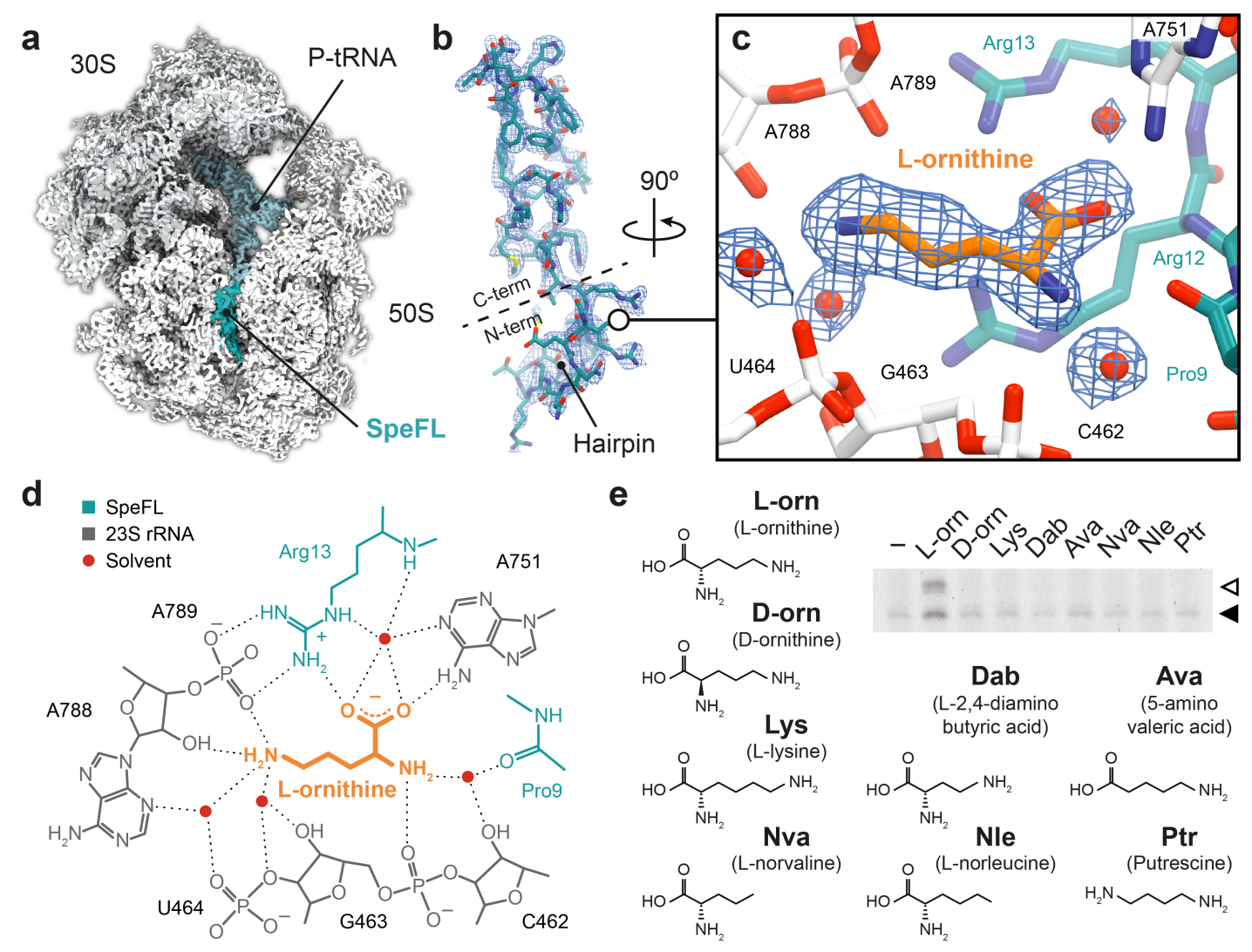

Figure 2 Structural basis for the specific recognition of L-ornithine by the SpeFL-70S complex. a, Transverse section of a cryo-EM density map of the SpeFL-70S complex, showing the small (30S, light gray) and large (50S, white) ribosomal subunits, the P-site tRNA (pale blue) and the SpeFL peptide (turquoise). b, Cryo-EM density displayed as a mesh, fitted with a molecular model of SpeFL, with the $\mathrm{N}$ - and $\mathrm{C}$-terminal domains highlighted. The $\mathrm{N}$-terminal hairpin is also indicated. c, Binding pocket formed by the 23S rRNA (white) and SpeFL (turquoise), with a single L-ornithine molecule (orange) surrounded by 4 solvent molecules (red) fitted into the cryo-EM density of the SpeFL-ESRF complex. The existence of these solvent molecules was validated using two independently determined structures of the SpeFL$70 S$ complex (see Supplementary Fig. 9). d, Chemical diagram showing interactions between the $23 \mathrm{~S}$ rRNA (dark gray), SpeFL (turquoise), L-ornithine (orange) and solvent molecules (red) inside the ligand binding pocket. Possible hydrogen bonds are shown as dotted lines. e, 
Toeprinting assay ${ }^{8,9}$ to monitor the translation of speFL in the absence $(-)$ or presence of 10 $\mathrm{mM}(+)$ of various small molecules in the presence of release factors (RF1,2,3). Arrows indicate ribosomes stalled with the indicated amino acid in the P-site (Ala33 - open triangle; Arg34 - filled triangle).

In the stalled SpeFL-70S termination complex, SpeFL adopts a compact fold that completely obstructs the upper two-thirds of the exit tunnel and can be subdivided into $\mathrm{N}$ - and C-terminal domains, corresponding to residues $1-13$ and 14-34 of SpeFL, respectively. The $\mathrm{N}$-terminal domain forms a hairpin, while secondary structure elements stabilize the C-terminal domain, most notably two type I $\beta$-turns between residues $19-22$ and $23-26$, and one $3_{10}$-helix between residues 27-32. In addition, SpeFL interacts extensively with the $23 \mathrm{~S}$ ribosomal RNA (23S rRNA) and with ribosomal proteins $u L 4$ and $u L 22$ through a combination of $\pi$-stacking, salt bridges and hydrogen bonding (Supplementary Fig. 8). All of these structural elements contribute to stabilizing the complex fold adopted by SpeFL inside the exit tunnel.

A clear peak of density that could be unambiguously attributed to a single L-ornithine molecule was visible inside a cavity formed by 23S rRNA residues C462, G463, U464, A751, A788 and A789 and by Pro9, Arg12 and Arg13 of the N-terminal domain of SpeFL, referred to here as the sensor domain (Fig. 2c, d and Supplementary Fig. 9). To our knowledge, this cavity represents a novel binding site for small molecules on the ribosome, which could be targeted for future antibiotic development (Supplementary Fig. 10). The ornithine recognition loop of SpeFL consists of a HIRRXXH motif spanning residues 10-16, among which His10, Arg13 and His16 help form the ligand-binding pocket by interacting with 23S rRNA and ribosomal protein uL22 residues (Fig 2c, d and Supplementary Fig. 8). Deletion of residues 1-7 of SpeFL, which disrupts the hairpin but retains the HIRRXXH motif (Supplementary Fig. 11), mutation of the strictly conserved Arg12 and Arg13 to alanine or lysine (Supplementary Fig. 12) or mutation of His10, Ile11 or His16 to alanine (Supplementary Fig. 13) abolished ornithine-dependent translational arrest in vitro, highlighting the importance of the hairpin and of the conserved residues of the HIRRXXH motif for the stalling process. The side chain and $\alpha$-amino groups of ornithine interact with the backbone phosphates of $23 \mathrm{~S}$ rRNA residues A789 and G463, respectively (Fig. $2 \mathrm{~d}$ ). Ornithine is further stabilized via hydrogen bonding between its $\alpha$-carboxyl group and both the guanidino group of SpeFL residue Arg13 and the N6-amino group of 23S rRNA residue A751. The availability of two independently obtained cryo-EM maps of the SpeFL-70S complex enabled us to accurately model and cross-validate the positions of ordered metal ions and solvent molecules within the complex. Four of these solvent molecules fill the cavity and make additional bridging interactions between ornithine and the 23S rRNA or SpeFL (Fig. 2c, d and Supplementary Fig. 9). Thus, small molecules differing from ornithine by only a single methylene group are either too short (L-2,4-diaminobutyric acid) or too long (L-lysine) for the binding pocket, while the deletion of ligand functional groups (putrescine, L-norvaline, Lnorleucine, 5-aminovaleric acid) or the use of a D-enantiomer (D-ornithine) abolish stalling by preventing the formation of certain hydrogen bonds (Fig. 2e and Supplementary Data 2). The tight coordination of L-ornithine via each of its potential hydrogen bond donors and acceptors therefore explains the high selectivity of SpeFL and the ribosome for their cognate ligand.

To understand how ornithine capture by the sensor domain stalls the ribosome, we must focus on the C-terminal effector domain of SpeFL, which consists of a hydrophobic core composed of four phenylalanine residues (Phe20, Phe28, Phe30 and Phe31) nucleated around the strictly conserved Phe26 (Fig. 3a and Supplementary Fig. 8). Residues Phe28, Phe30 and Phe31 establish $\pi$-stacking interactions with the bases of $23 \mathrm{~S}$ rRNA residues U2586, G2505 and A2062, respectively, which help to position the effector domain in the upper part of the ribosomal exit tunnel (Fig. 3a, Supplementary Fig. 8). Mutation of Phe26 or any of these three aromatic residues to alanine abolishes or severely impairs ribosome stalling in vitro (Fig. $3 \mathrm{~b}$ and 
Supplementary Data 3), highlighting their importance for translational arrest. Since the SpeFL$70 \mathrm{~S}$ structure corresponds to stalled ribosomes with a UAG stop codon in the A-site, it is clear that SpeFL must inhibit the action of RF1, the release factor responsible for recognizing this stop codon. Comparing our structure with that of a Thermus thermophilus 705 ribosome in complex with RF1 and a P-site tRNA ${ }^{15}$ reveals that the binding of RF1 to the SpeFL-70S complex is prevented by $23 \mathrm{~S}$ rRNA residue $\mathrm{U} 2585$, which adopts a conformation that would sterically clash with the GGQ loop of RF1. The movement of U2585 is caused by residue Asn32 of SpeFL, which takes the place of its base in the 70S-RF1-P-tRNA complex (Fig. 3c, d). The nature of residue 32 is likely not to be critical for stalling as even an N32A mutant undergoes ornithine-dependent translational arrest (Fig. 3b and Supplementary Data 3). Moreover, the identity of the release factor is not important as all possible stop codons are observed for speFL across different species (Supplementary Fig. 1). Thus, the continued synthesis of SpeFL after the recognition of ornithine by the sensor domain leads to the compaction of the effector domain and forces $U 2585$ into a conformation that prevents release factor action, causing the ribosome to stall.
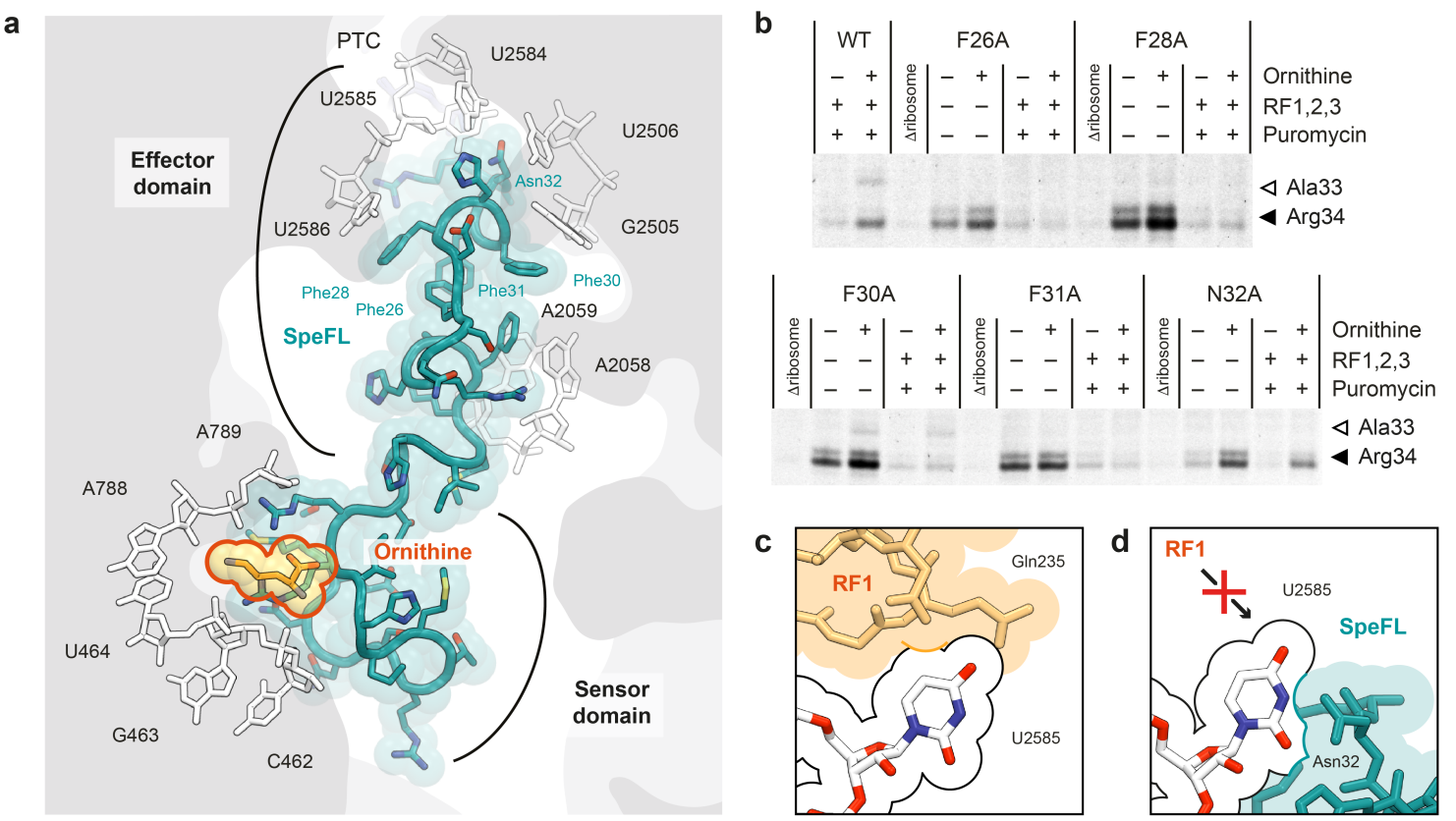

Figure 3 | Inhibition of peptide release by SpeFL. a, Close-up of the ribosomal exit tunnel showing the sensor and effector domains of SpeFL (turquoise) interacting with residues of the 23S rRNA (white). Ornithine (orange) is trapped between the tunnel wall and the sensor domain, while synthesis of all 34 amino acids of SpeFL leads to compaction of the effector domain and blockage of the peptidyl transferase center (PTC). b, Toeprinting assay ${ }^{8,9}$ to monitor the translation of wild-type (WT) and mutant speFL in the absence (-) or presence (+) of $10 \mathrm{mM}$ ornithine or $90 \mu \mathrm{M}$ puromycin. Arrows indicate ribosomes stalled with the indicated amino acid in the P-site (Ala33 - open triangle; Arg34 - filled triangle). c, Structure of an E. coli 70S-RF1-P-tRNA complex (PDB 5J3C) ${ }^{15}$, showing the GGQ loop of RF1 (peach, with residue Gln-235 labeled) and 23S rRNA residue U2585 (white). d, Close-up of the SpeFL-70S structure showing the same view as in c. Residue Asn32 of SpeFL (turquoise) forces U2585 to adopt a conformation that prevents RF1 binding.

Metabolite sensing by a translating ribosome is a complex and dynamic process whose understanding has been hampered by the lack of high-resolution structural data ${ }^{11,16-18}$. With the exception of antibiotic-dependent translational arrest ${ }^{19-21}$, in which the drug binds directly to the empty ribosome, it is not known if the metabolite helps to create a binding surface for the 
nascent peptide or vice versa ${ }^{11}$, even though the latter has been suggested for the binding of tryptophan to the nascent TnaC peptide ${ }^{17}$. In the SpeFL-70S structure, ornithine interacts primarily with the ribosome, either directly or via bridging solvent molecules, whereas SpeFL provides only a few stabilizing interactions that help capture the cognate ligand (Fig. $2 \mathrm{~d}$ ). This implies that ornithine is already loosely associated with the 23S rRNA prior to the arrival of the SpeFL sensor domain (Fig. 4), as suggested by molecular dynamics simulations pointing to the existence of binding crevices for different amino acid side chains within the ribosomal exit tunnel $^{22}$. Additionally, the close proximity of the sensor domain to the tunnel constriction formed by ribosomal proteins uL4 and uL22 raises the possibility that the sensor domain begins to fold in the upper part of the exit tunnel, consistent with the decreased spe $F$ expression seen for the $\mathrm{R} 12_{\mathrm{r}} \mathrm{R} 13_{\mathrm{c}}$ mutant (Fig. 1f). Indeed, a partially folded sensor hairpin emerging from the tunnel constriction could rapidly contact and fix an ornithine molecule present within its adjacent binding crevice on the $23 \mathrm{~S}$ rRNA. Once the interaction between the sensor domain and the tunnel wall has been stabilized through the binding of ornithine, the effector domain can be synthesized and compacted, resulting in the inhibition of peptide release from the ribosome. Since metabolite recognition must occur before SpeFL is fully synthesized, this process has to operate under a kinetic regime. In other words, the concentration of free ornithine must be significantly above the $K_{D}$ of the interaction, resulting in a rate of metabolite binding that is greater than the rate of SpeFL synthesis. This increases the likelihood that ligand recognition takes place by ensuring that ornithine is present within its binding pocket when the sensor domain of SpeFL reaches the corresponding region of the exit tunnel. Such a scenario is reminiscent of kinetically controlled riboswitches, which require high ligand concentrations to ensure that metabolite binding occurs faster than RNA transcription ${ }^{23}$. These basic strategies for ligand recognition could be used by other metabolite-sensing nascent peptides.

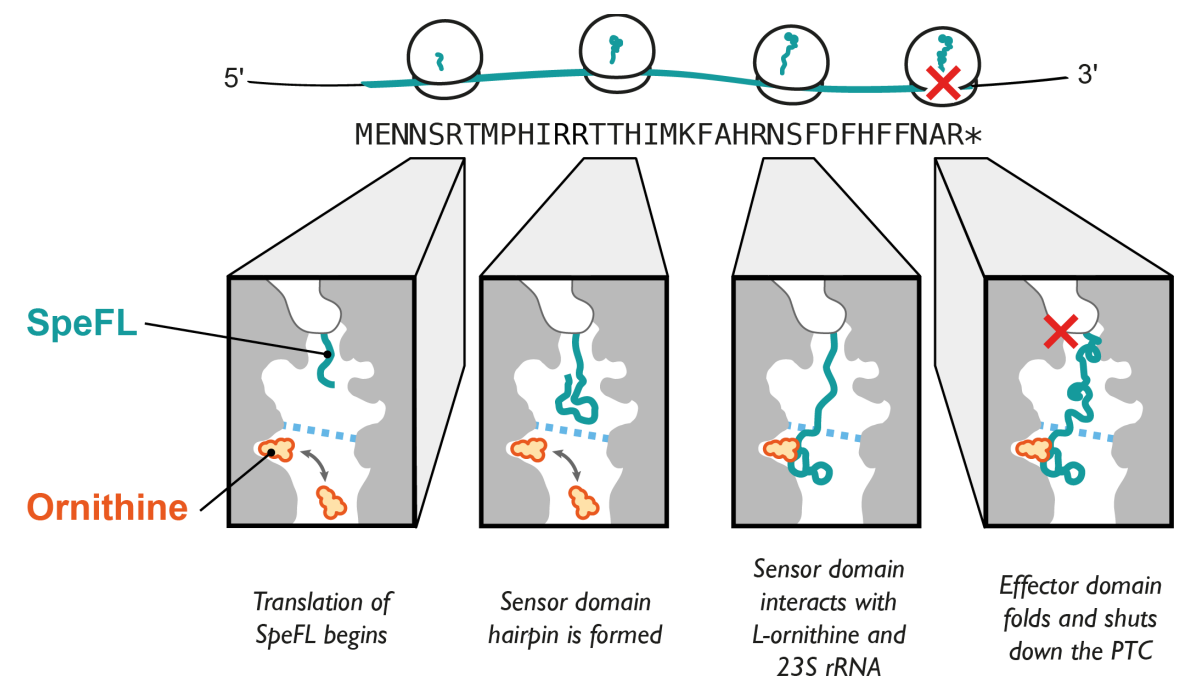

Figure 4 | Mechanism of ornithine sensing and capture by the SpeFL-70S complex. Model for the binding of ornithine (orange) by the ribosome and SpeFL (turquoise), leading to inactivation of the peptide release activity of the ribosome (red cross). The tunnel constriction is shown as a blue dotted line.

In conclusion, our data reveal how the ribosome aided by SpeFL functions as a highly selective ornithine sensor to regulate polyamine biosynthesis in pathogenic bacteria like $E$. coli or $S$. Typhimurium. Both speF and potE, whose expression is regulated by SpeFL in response to fluctuating ornithine levels, have been linked to biofilm formation and microbial virulence ${ }^{24-26}$. However, the exact physiological roles of the $s p e F$ operon remain unclear. A recent study on interspecies niche modulation during mixed Enterococcus faecalis (E. faecalis) and uropathogenic $E$. coli infections ${ }^{27}$ may provide us with a clue in this regard. In this work, 
ornithine secreted by E. faecalis helps uropathogenic E. coli grow in the iron-restricted environment of a human host by redirecting its metabolism towards siderophore production. Since we know that $E$. faecalis lowers the $\mathrm{pH}$ of the polymicrobial culture by producing lactic acid and that low $\mathrm{pH}$ and ornithine are required for speF induction, it is reasonable to assume that SpeFL could play a role in this E. faecalis-driven promotion of E. coli growth. Indeed, ornithine produced by $E$. faecalis might be sensed by SpeFL to trigger the expression of SpeF, which in turn decarboxylates ornithine into putrescine. Putrescine turns on the expression of a number of genes ${ }^{28}$, including the sigma factor $\mathrm{Fecl}$, a protein that activates the ferric citrate uptake operon fec $A B C D E$. Ferric citrate is a naturally abundant compound inside the host, which allows uropathogenic $E$. coli to grow under iron limiting conditions ${ }^{29}$. Although a direct link between ornithine secreted by $E$. faecalis and ferric citrate uptake has yet to be demonstrated, it is known that the production of the siderophores enterobactin and yersiniabactin is stimulated in this manner ${ }^{27}$. Thus, a possible involvement of SpeFL in sensing ornithine cues within polymicrobial communities of this kind must now be examined.

Acknowledgements A.H.V. is funded by a doctoral grant from the French Ministère de I'Enseignement Supérieur et de la Recherche. C.A.I., B.S. and G.S. have received funding for this project from the European Research Council (ERC) under the European Union's Horizon 2020 research and innovation program (Grant Agreement No. 724040). C.A.I. is an EMBO YIP and has received funding from the Fondation Bettencourt-Schueller. I.C-M. is funded by Inserm and A.C.S. is funded by a joint doctoral grant from Inserm and the Aquitaine Regional Council. We acknowledge Diamond for access and support of the Cryo-EM facilities at the UK national electron bio-imaging centre (eBIC), (proposal EM 19716-1), funded by the Wellcome Trust, MRC and BBSRC, and Sarah Neumann, Andrew Howe and James Gilchrist for assistance. We also acknowledge the European Synchrotron Radiation Facility for provision of microscope time on $\mathrm{CMO}^{30}$ and we thank Michael Hons for his assistance. This work has been supported by iNEXT, grant number 3901, funded by the Horizon 2020 program of the European Union. We thank Isabelle lost for help with gradient fractionation, Yaser Hashem, Armel Bezault and Marion Decossas for help with grid preparation and screening, Rémi Fronzes for access to the GPU cluster, Chiara Rapisarda for help with cryo-EM data processing and Nora VazquezLaslop for providing the E. coli TB1 strain and pErmZ $\alpha$ plasmid for the in vivo lacZ assay.

Author contributions C.A.I. and B.S. designed the study. I.C-M. identified speFL. A.H.V., B.S., G.S. and A.C.S. performed biochemical experiments. A.H.V. performed bacterial assays. A.H.V. prepared the cryo-EM sample. A.H.V. and C.A.I. processed the cryo-EM data. A.H.V., B.S., G.S., A.C.S. and C.A.I. interpreted the results. A.H.V., B.S. and C.A.I. wrote the paper.

Competing financial interests The authors declare no competing financial interests. Correspondence and requests for materials should be addressed to C.A.I. (axel.innis@inserm.fr). 


\section{METHODS}

No statistical methods were used to predetermine sample size. The experiments were not randomized and investigators were not blinded to allocation during experiments and outcome assessment.

Bioinformatic identification of speFL. Homologs of $E$. coli speF were identified using tblastn ${ }^{31}$ (E-value lower than $10^{-4},>70 \%$ coverage), redundancy was minimized using $\mathrm{CD}-\mathrm{Hit}^{32}(95 \%$ sequence identity cutoff) and regions between spe $F$ and the nearest upstream annotated genes were compiled (unknown, hypothetical, uncharacterized or leader genes were considered not to be annotated). All possible forward ORFs within the last 500 nucleotides of these upstream regions were extracted, considering ATG and alternative start codons defined for bacterial, archaeal and plant plastid genetic codes (NCBI Genetic codes Table 11). Possible ShineDalgarno sequences were not taken into account. In cases where more than one ORF was possible, the longest ORF was kept. Redundancy within the ORFs thus obtained was minimized with CD-Hit (95\% sequence identity cutoff). A pairwise comparison of the resulting ORFs was then carried out as follows. First, nucleotide sequences were translated into amino acid sequences. A sliding window of 10 amino acids was applied to each sequence and an alignment score based on a BLOSUM $62^{33}$ substitution matrix was computed for all possible combinations of 10-amino acid fragments from each pair of ORFs (no gaps allowed). A graph in which each node represents a 10-amino acid fragment and each edge represents an alignment score greater than 10 between two fragments (with the alignment score as a weight) was constructed. Finally, we used $M C^{34,35}$ to identify clusters within this graph and found a major cluster of conserved upstream ORFs corresponding to speFL.

Phylogeny of speFL. Homologs of E. coli speFL were identified using $\operatorname{tblastn}^{31}$ and a phylogenetic analysis of $s p e F L$ from 15 representative species of $\gamma$-proteobacteria was carried out using the EMBL-EBI Simple Phylogeny server ${ }^{36}$. The resulting tree was displayed with Dendroscope $^{37}$ (Supplementary Fig. 1).

Toeprinting assays. Toeprinting was performed as described previously ${ }^{9}$. Briefly, DNA templates containing a T7 promoter, a ribosome binding site, wild-type or mutant $s p e F L$, the first 75 nucleotides of the speFL-speF intergenic region and the NV1 sequence ${ }^{38}$ were generated or amplified by polymerase chain reaction (PCR). The wild-type template was amplified by PCR from E. coli DH5 $\alpha$ genomic DNA using oligonucleotides 1, 2 and 3 followed by PCR amplification of the product with oligonucleotides 4 and 5 (see Supplementary Table 1 for the sequences of all oligonucleotides used). The speFL- $\Delta 1-7$ template was obtained using the same protocol as for the wild type, but substituting oligonucleotide 2 with 6 . Templates with point mutations and the double frame-shifted template $s p e F L_{f s}$ were purchased as gBlocks from IDT and amplified with oligonucleotides 4 and 5 (see Supplementary Table 2 for the sequences of all DNA templates). DNA templates were transcribed and translated in vitro using the PURExpress $\Delta$ RF123 system (New England Biolabs). Ligands were dissolved in water and added as needed at the beginning of the reaction. A Yakima Yellow-labeled probe $(2 \mu \mathrm{M})$ complementary to the NV1 sequence ${ }^{38}$ was added to the $5 \mu \mathrm{L}$ reaction after incubating for 60 minutes at $30^{\circ} \mathrm{C}$, and the sample was incubated for another 5 minutes at the same temperature. When needed, samples were treated with $90 \mu \mathrm{M}$ puromycin at $30^{\circ} \mathrm{C}$ for 3 minutes, immediately followed by reverse transcription with $50 \mathrm{U}$ of AMV reverse transcriptase (Promega) for 20 minutes at $30^{\circ} \mathrm{C}$. RNA was degraded by adding $0.5 \mu \mathrm{L}$ of a $10 \mathrm{M} \mathrm{NaOH}$ stock at $30^{\circ} \mathrm{C}$ for 15 minutes. Samples were neutralized with $0.7 \mu \mathrm{L}$ of a $7.5 \mathrm{M} \mathrm{HCl}$ stock and the remaining CDNA was purified using a nucleotide removal kit (Qiagen). Sequencing reactions were performed according to the method of Sanger. Briefly, 1 pmol of DNA template was 
mixed with 10 pmol of oligonucleotide 9 labeled with Yakima Yellow and $1 \mu \mathrm{L}$ of HemoKlen Taq DNA Polymerase (New England Biolabs) in a $6 \mu \mathrm{L}$ reaction mixture containing $50 \mathrm{mM}$ Tris$\mathrm{HCl} \mathrm{pH} \mathrm{9.0,2} \mathrm{mM} \mathrm{MgCl} 2,6.6 \mu \mathrm{M}$ dNTPs, $10 \mu \mathrm{M}$ ddGTP, $117 \mu \mathrm{M}$ ddATP, $200 \mu \mathrm{M}$ ddTTP or 66 $\mu \mathrm{M}$ ddCTP. Primers were extended with 30 cycles of 30 seconds of annealing at $42{ }^{\circ} \mathrm{C}$ and 1 minute of elongation at $70{ }^{\circ} \mathrm{C}$. The purified cDNA and sequencing reactions were dried using a SpeedVac and resuspended in $6 \mu \mathrm{l}$ or $3.5 \mu \mathrm{l}$ gel-loading buffer $(95 \%$ formamide, $0.25 \%(\mathrm{w} / \mathrm{v})$ xylene cyanol, $0.25 \%(\mathrm{w} / \mathrm{v}) \mathrm{SDS}$ ), respectively. Samples were denatured at $95^{\circ} \mathrm{C}$ for 5 minutes, and $2 \mu \mathrm{L}$ of the sequencing reactions and $3 \mu \mathrm{L}$ of the toeprinting were separated by $7.5 \%$ sequencing PAGE (2000 V, $40 \mathrm{~W}$ for 2-2.5h) followed by detection on a Typhoon imager (GE).

$\boldsymbol{\beta}$-galactosidase assay. To test for in vivo activity, a translational reporter plasmid was obtained by fusing a region containing $s p e F L$, the spe $F L-s p e F$ intergenic region and the first three codons of spe $F$ to lacZ $\alpha$. The insert was prepared by PCR amplification from the E. coli K12 genome using oligonucleotides 7 and 8 . Oligonucleotides 9 and 10 were used to linearize the pErmZ $\alpha$ plasmid $^{39}$. The insert and linearized plasmid were mixed and transformed following the AQUA cloning protocol $^{40}$. Plasmids containing point mutations in the R12-R13 region were generated by site-directed mutagenesis as follows. The wild-type plasmid was linearized by PCR amplification with oligonucleotides 11 and 12, 13 or 14 (the latter included the mutations). The PCR product was purified from a $2 \%$ TAE-agarose gel with a Gel Extraction Kit (Qiagen) and phosphorylated for 30 minutes at $37{ }^{\circ} \mathrm{C}$ with $4 \mathrm{U}$ of T4 Polynucleotide Kinase (New England Biolabs) in a total volume of $20 \mu \mathrm{l}$ according to the manufacturer's instructions. The plasmid was circularized again by incubating the phosphorylated product with $400 \mathrm{U}$ of T4 DNA ligase (New England Biolabs) for 2 hours at $16^{\circ} \mathrm{C}$. The plasmids were transformed into E. coli TB1 ${ }^{39}$ and the cells were grown in lysogeny broth $(\mathrm{LB})$ at $37^{\circ} \mathrm{C}(200 \mathrm{rpm})$ with streptomycin $(50 \mu \mathrm{g} / \mathrm{ml})$ and ampicillin $(100 \mu \mathrm{g} / \mathrm{ml})$ until they reached an optical density of 0.6 at $600 \mathrm{~nm} .5 \mu \mathrm{L}$ of the cell culture were plated onto LB-agar plates supplemented with streptomycin, ampicillin, $1 \mathrm{mM}$ Isopropyl- $\beta$-D-1-thiogalactopyranoside (IPTG) and $0.5 \mathrm{mM}$ 5-bromo-4-chloro-3-indolyl-beta-Dgalactopyranoside (X-gal). $20 \mu \mathrm{g}$ of bicyclomycin (Santa Cruz Biotechnology) or 0-3 $\mu \mathrm{mol}$ of Lornithine (Sigma) were added after a 6 hour incubation at $37^{\circ} \mathrm{C}$. The plates were then incubated at $37^{\circ} \mathrm{C}$ overnight and pictures were taken the next day.

Preparation of an $\boldsymbol{E}$. coli SpeFL-70S complex for cryo-EM. The SpeFL-70S complex was prepared using a modified disome purification strategy ${ }^{20}$. Briefly, SpeFL was expressed in an RTS $100 \mathrm{E}$. coli $\mathrm{HY}$ Kit (Biotechrabbit) for 1 hour at $30^{\circ} \mathrm{C}$ in the presence of $10 \mathrm{mM}$ L-ornithine if indicated, using a pEX-K4-SpeFL_2x plasmid (Eurofins) that carries two copies of speFL arranged as a bicistronic mRNA (Supplementary Fig. 5; insert sequence: 5'-CGA-TCG-AATTCT-AAT-ACG-ACT-CAC-TAT-AGG-GCT-TAA-GTA-TAA-GGA-GGA-AAA-AAT-ATG-GAAAAT-AAC-AGC-CGC-ACT-ATG-CCC-CAT-ATA-AGG-CGG-ACA-ACT-CAT-ATT-ATG-AAGTTT-GCT-CAT-CGC-AAT-AGC-TTC-GAC-TTT-CAC-TTC-TTC-AAT-GCC-CGT-TAG-TCT-ACCGAC-TAA-GGG-CAC-TTC-AGC-TAA-AGT-TTT-ATA-AGG-AGG-AAA-AAA-TAT-GGA-AAATAA-CAG-CCG-CAC-TAT-GCC-CCA-TAT-AAG-GCG-GAC-AAC-TCA-TAT-TAT-GAA-GTTTGC-TCA-TCG-CAA-TAG-CTT-CGA-CTT-TCA-CTT-CTT-CAA-TGC-CCG-TTA-GTC-TAC-CGACTA-AGG-GCA-CTT-CAG-CTA-GAT-ATC-TAG-CAT-AAC-CCC-TTG-GGG-CCT-CTA-AACGGG-TCT-TGA-GGG-GTT-TTT-TG-3'). Reaction volumes of $50 \mu \mathrm{L}$ and $750 \mu \mathrm{L}$ were used for analytical and preparative purposes, respectively. When indicated, the reaction was treated with $100 \mu \mathrm{M}$ puromycin for 3 minutes at $30^{\circ} \mathrm{C}$ before being layered over $10-40 \%(\mathrm{w} / \mathrm{v})$ sucrose gradients containing Buffer A $(50 \mathrm{mM}$ HEPES-KOH pH 7.5, $100 \mathrm{mM} \mathrm{K}$-acetate, $25 \mathrm{mM} \mathrm{Mg-}$ acetate and $10 \mathrm{mM}$ L-ornithine), prepared using a Gradient Master 108 (Biocomp). Sucrose gradient ultracentrifugation was performed for 2 hours and 45 minutes at 35,000 rpm in a SW $41 \mathrm{Ti}$ rotor (Beckman-Coulter) at $4^{\circ} \mathrm{C}$. Polysome fractions were detected and collected using a UV detection system (UA-6, Teledyne ISCO) coupled to a gradient fractionator (Foxy R1, Teledyne ISCO). Polysomes were washed in $100 \mathrm{kDa}$ molecular weight cutoff (MWCO) spin 
concentrators to remove sucrose, concentrate ribosomes and replace the solution with Buffer A. The concentration of ribosomes was inferred by measuring the absorbance of the sample at 260 $\mathrm{nm}\left(1 \mathrm{~A}_{260}=60 \mu \mathrm{g} / \mathrm{ml}\right.$ or $\left.24 \mathrm{nM}\right)$ with a NanoDrop One (ThermoFisher). For analytical purposes, $13.2 \mathrm{pmol}$ of ribosomes with an excess of $10 \mathrm{nmol}$ of rnase $\mathrm{H}$ oligonucleotide were incubated for 1 hour at $25^{\circ} \mathrm{C}$ with $7.5 \mathrm{U}$ of RNase $\mathrm{H}$ or without it (RNase $\mathrm{H}$-control). The sample for cryo-EM grid preparation was treated with $75 \mathrm{U}$ of RNase $\mathrm{H}$ (New England Biolabs) per $250 \mathrm{pmol}$ of ribosomes for one hour at $25^{\circ} \mathrm{C}$ in the presence of $5 \mathrm{nmol}$ of oligonucleotide 15. The monosomes obtained after RNAse $\mathrm{H}$ treatment were isolated by sucrose gradient ultracentrifugation as described above. The sample was flash frozen in liquid nitrogen and stored at $-80^{\circ} \mathrm{C}$.

Cryo-EM grid preparation. Frozen SpeFL-70S complex was thawed and diluted in Storage Buffer to yield a final concentration of $120 \mathrm{nM}$. Quantifoil carbon grids (QF-R2/2-Cu) were coated with a thin carbon layer prepared using an Edwards Vacuum Carbon Coater E306. Grids were glow discharged for 30 seconds at $2 \mathrm{~mA}$ before application of $4 \mu \mathrm{L}$ of the SpeFL-70S complex. After blotting for 2 seconds and waiting for 30 seconds, grids were plunge-frozen in liquid ethane using a Vitrobot (FEI) set to $4^{\circ} \mathrm{C}$ and $100 \%$ humidity.

Cryo-EM data acquisition and processing. Grids were imaged using two 300-keV Titan Krios (FEI) equipped with a K2 Summit direct electron detector (Gatan) at ESRF (France) and at the Diamond Light Source (eBIC, UK) producing the SpeFL-ESRF and SpeFL-DLS datasets, respectively. Images were recorded with EPU in counting mode with a magnified pixel size of $1.067 \AA$ (Supplementary Table 3). 30 frames were collected to have a total accumulated dose of 30 electrons per $\AA^{2}$. Data were processed in Relion 2.14, Relion 3.0 $0^{42}$ and Cryosparc $0.6^{43}$ according to the scheme presented in Supplementary Figure 6. Briefly, MotionCor $2^{44}$ was used for movie alignment, Gctf ${ }^{45}$ for Contrast Transfer Function (CTF) estimation and either Relion 2.1 or Cryosparc for 2D classification of the particles obtained by automated picking in Relion 2.1. The csparc2star.py and star.py scripts ${ }^{46}$ were used for exporting particles selected in Cryosparc back into Relion. 3D classification was performed in Relion 2.1 in three steps: (i) unsupervised classification with 4 times downsized particles, (ii) focused classification on all 3 tRNA sites with background subtraction and 3 times downsized particles, and (iii) focused classification on the P-site tRNA with background subtraction and 2 times downsized particles. Classes containing a single P-tRNA or both P- and E-site tRNAs were combined after ensuring that each class contained a peptide with the same conformation in the ribosomal exit tunnel when refined individually. Movie refinement and particle polishing were first performed with Relion 2.1. Refined particle coordinates were then used to re-extract particles in Relion 3.0 in order to perform per particle CTF and beam tilt refinement, followed by Bayesian polishing.

Model building and refinement. An initial model of the SpeFL-70S complex was obtained by placing the coordinates for an E. coli $70 S$ ribosome (PDB $4 \cup 27)^{47}$ into the cryo-EM density map with Situs ${ }^{48}$, using the colores routine for the initial fit at $15 \AA$ and the collage routine for fitting subdomains of the ribosome (30S body, 30 S head, 30 S spur, $50 S$ body and L1 stalk) as independent rigid bodies at progressively higher resolutions until reaching the map resolution. The pixel size was optimized by generating post-processed maps with different pixel sizes in Relion 2.1 and assessing the map-to-model correlation after real space refinement in Phenix ${ }^{49}$ with the initial model. A model for the SpeFL peptide was built manually with $\operatorname{Coot}^{50}$ and refined through multiple rounds of real-space refinement in Phenix and manual rebuilding in Coot. The model was validated with MolProbity ${ }^{51}$. Automatic map sharpening was performed in Phenix using a refined model from which L-ornithine had been removed (Supplementary Fig. 7 and 9). The quality of the sharpened maps was such that ordered ions and solvent molecules could be modeled into the density and validated using the two structural replicates. Hydrated magnesium ion clusters were identified on the basis of their distinctive cryo-EM density. The 
identity of individual magnesium and potassium ions could be inferred by analogy with a recent X-ray structure of the Thermus thermophilus ribosome ${ }^{52}$. All other solvent molecules were modeled as unknown atom and residue types. The resulting map was used to prepare all figures except Fig. 2a, for which a post-processed map from Relion was used (sharpening Bfactor of -10$)$.

Figure preparation. Figures showing cryo-EM density or atomic models were prepared using Chimera $^{53}{ }^{3}$ Chimera $X^{54}$ or Pymol Molecular Graphics Systems (version 1.7.4 Schrödinger) ${ }^{55}$.

Data availability. The SpeFL-ESRF and SpeFL-DLS structures were deposited in the RCSB PDB with accession codes 6TC3 and 6TBV, and cryo-EM maps were deposited in the EMDB with accession codes EMD-10458 and EMD-10453.

\section{REFERENCES}

1 Michael, A. J. Polyamine function in archaea and bacteria. / Biol Chem 293, 1869318701 (2018).

2 Miller-Fleming, L., Olin-Sandoval, V., Campbell, K. \& Ralser, M. Remaining Mysteries of Molecular Biology: The Role of Polyamines in the Cell. J Mol Biol 427, 3389-3406 (2015).

3 Shah, P. \& Swiatlo, E. A multifaceted role for polyamines in bacterial pathogens. Mol Microbiol 68, 4-16 (2008).

4 Kashiwagi, K. et al. Coexistence of the genes for putrescine transport protein and ornithine decarboxylase at $16 \mathrm{~min}$ on Escherichia coli chromosome. J Biol Chem 266, 20922-20927 (1991).

5 Kashiwagi, K., Shibuya, S., Tomitori, H., Kuraishi, A. \& Igarashi, K. Excretion and uptake of putrescine by the PotE protein in Escherichia coli. J Biol Chem 272, 63186323 (1997).

6 Kashiwagi, K., Watanabe, R. \& Igarashi, K. Involvement of ribonuclease III in the enhancement of expression of the speF-potE operon encoding inducible ornithine decarboxylase and polyamine transport protein. Biochem Biophys Res Commun 200, 591-597 (1994).

7 Ben-Zvi, T. et al. mRNA dynamics and alternative conformations adopted under low and high arginine concentrations control polyamine biosynthesis in Salmonella. PLoS Genet 15, e1007646 (2019).

8 Hartz, D., McPheeters, D. S., Traut, R. \& Gold, L. Extension inhibition analysis of translation initiation complexes. Methods Enzymol 164, 419-425 (1988).

9 Seefeldt, A. C. et al. The proline-rich antimicrobial peptide Onc112 inhibits translation by blocking and destabilizing the initiation complex. Nat Struct Mol Biol 22, 470-475 (2015).

10 Ito, K. \& Chiba, S. Arrest peptides: cis-acting modulators of translation. Annu Rev Biochem 82, 171-202 (2013).

11 Seip, B. \& Innis, C. A. How Widespread is Metabolite Sensing by Ribosome-Arresting Nascent Peptides? J Mol Biol 428, 2217-2227 (2016).

12 Magyar, A., Zhang, X., Kohn, H. \& Widger, W. R. The antibiotic bicyclomycin affects the secondary RNA binding site of Escherichia coli transcription termination factor Rho. J Biol Chem 271, 25369-25374 (1996).

13 Di Salvo, M., Puccio, S., Peano, C., Lacour, S. \& Alifano, P. RhoTermPredict: an algorithm for predicting Rho-dependent transcription terminators based on Escherichia coli, Bacillus subtilis and Salmonella enterica databases. BMC Bioinformatics 20, 117 (2019). 
14 Gong, F. \& Yanofsky, C. Analysis of tryptophanase operon expression in vitro: accumulation of TnaC-peptidyl-tRNA in a release factor 2-depleted S-30 extract prevents Rho factor action, simulating induction. I Biol Chem 277, 17095-17100 (2002).

15 Pierson, W. E. et al. Uniformity of Peptide Release Is Maintained by Methylation of Release Factors. Cell Rep 17, 11-18 (2016).

16 Bhushan, S. et al. Structural basis for translational stalling by human cytomegalovirus and fungal arginine attenuator peptide. Mol Cell 40, 138-146 (2010).

17 Bischoff, L., Berninghausen, O. \& Beckmann, R. Molecular basis for the ribosome functioning as an L-tryptophan sensor. Cell Rep 9, 469-475 (2014).

18 Seidelt, B. et al. Structural insight into nascent polypeptide chain-mediated translational stalling. Science 326, 1412-1415 (2009).

19 Arenz, S. et al. A combined cryo-EM and molecular dynamics approach reveals the mechanism of ErmBL-mediated translation arrest. Nat Commun 7, 12026 (2016).

20 Arenz, S. et al. Drug sensing by the ribosome induces translational arrest via active site perturbation. Mol Cell 56, 446-452 (2014).

21 Arenz, S. et al. Molecular basis for erythromycin-dependent ribosome stalling during translation of the ErmBL leader peptide. Nat Commun 5, 3501 (2014).

22 Petrone, P. M., Snow, C. D., Lucent, D. \& Pande, V. S. Side-chain recognition and gating in the ribosome exit tunnel. Proc Natl Acad Sci U S A 105, 16549-16554 (2008).

23 Coppins, R. L., Hall, K. B. \& Groisman, E. A. The intricate world of riboswitches. Curr Opin Microbiol 10, 176-181 (2007).

24 Ding, Y., Peng, N., Du, Y., Ji, L. \& Cao, B. Disruption of putrescine biosynthesis in Shewanella oneidensis enhances biofilm cohesiveness and performance in $\mathrm{Cr}(\mathrm{VI})$ immobilization. Appl Environ Microbiol 80, 1498-1506 (2014).

25 Guerra, P. R. et al. Putrescine biosynthesis and export genes are essential for normal growth of avian pathogenic Escherichia coli. BMC Microbiol 18, 226 (2018).

26 Wang, Y., Wang, F., Wang, C., Li, X. \& Fu, L. Positive Regulation of Spoilage Potential and Biofilm Formation in Shewanella baltica OS155 via Quorum Sensing System Composed of DKP and Orphan LuxRs. Front Microbiol 10, 135 (2019).

27 Keogh, D. et al. Enterococcal Metabolite Cues Facilitate Interspecies Niche Modulation and Polymicrobial Infection. Cell Host Microbe 20, 493-503 (2016).

28 Yoshida, M. et al. A unifying model for the role of polyamines in bacterial cell growth, the polyamine modulon. J Biol Chem 279, 46008-46013 (2004).

29 Robinson, A. E., Heffernan, J. R. \& Henderson, J. P. The iron hand of uropathogenic Escherichia coli: the role of transition metal control in virulence. Future Microbiol 13, 745-756 (2018).

30 Kandiah, E. et al. CM01: a facility for cryo-electron microscopy at the European Synchrotron. Acta Crystallogr D Struct Biol 75, 528-535 (2019).

31 Altschul, S. F., Gish, W., Miller, W., Myers, E. W. \& Lipman, D. J. Basic local alignment search tool. J Mol Biol 215, 403-410 (1990).

$32 \mathrm{Li}, \mathrm{W}$., Jaroszewski, L. \& Godzik, A. Clustering of highly homologous sequences to reduce the size of large protein databases. Bioinformatics 17, 282-283 (2001).

33 Henikoff, S. \& Henikoff, J. G. Amino acid substitution matrices from protein blocks. Proc Natl Acad Sci U S A 89, 10915-10919 (1992).

34 Enright, A. J., Van Dongen, S. \& Ouzounis, C. A. An efficient algorithm for large-scale detection of protein families. Nucleic Acids Res 30, 1575-1584 (2002).

35 Van Dongen, S. Graph Clustering by Flow Simulation PhD thesis, University of Utrecht, (2000).

36 Chojnacki, S., Cowley, A., Lee, J., Foix, A. \& Lopez, R. Programmatic access to bioinformatics tools from EMBL-EBI update: 2017. Nucleic Acids Res 45, W550-W553 (2017). 
37 Huson, D. H. et al. Dendroscope: An interactive viewer for large phylogenetic trees. BMC Bioinformatics 8, 460 (2007).

38 Vazquez-Laslop, N., Thum, C. \& Mankin, A. S. Molecular mechanism of drugdependent ribosome stalling. Mol Cell 30, 190-202 (2008).

39 Bailey, M., Chettiath, T. \& Mankin, A. S. Induction of erm $(\mathrm{C})$ expression by noninducing antibiotics. Antimicrob Agents Chemother 52, 866-874 (2008).

40 Beyer, H. M. et al. AQUA cloning: a versatile and simple enzyme-free cloning approach. PloS one 10, e0137652 (2015).

41 Scheres, S. H. RELION: implementation of a Bayesian approach to cryo-EM structure determination. J Struct Biol 180, 519-530 (2012).

42 Zivanov, J., Nakane, T. \& Scheres, S. H. W. A Bayesian approach to beam-induced motion correction in cryo-EM single-particle analysis. IUCrJ 6, 5-17 (2019).

43 Punjani, A., Rubinstein, J. L., Fleet, D. J. \& Brubaker, M. A. cryoSPARC: algorithms for rapid unsupervised cryo-EM structure determination. Nat Methods 14, 290-296 (2017).

44 Zheng, S. Q. et al. MotionCor2: anisotropic correction of beam-induced motion for improved cryo-electron microscopy. Nat Methods 14, 331-332 (2017).

45 Zhang, K. Gctf: Real-time CTF determination and correction. J Struct Biol 193, 1-12 (2016).

46 UCSF PyEM (2016).

47 Noeske, J. et al. Synergy of streptogramin antibiotics occurs independently of their effects on translation. Antimicrob Agents Chemother 58, 5269-5279 (2014).

48 Wriggers, W. \& Birmanns, S. Using situs for flexible and rigid-body fitting of multiresolution single-molecule data. J Struct Biol 133, 193-202 (2001).

49 Afonine, P. V. et al. Real-space refinement in PHENIX for cryo-EM and crystallography. Acta Crystallogr D Struct Biol 74, 531-544 (2018).

50 Emsley, P. \& Cowtan, K. Coot: model-building tools for molecular graphics. Acta Crystallogr D Biol Crystallogr 60, 2126-2132 (2004).

51 Williams, C. J. et al. MolProbity: More and better reference data for improved all-atom structure validation. Protein Sci 27, 293-315 (2018).

52 Rozov, A. et al. Importance of potassium ions for ribosome structure and function revealed by long-wavelength X-ray diffraction. Nat Commun 10, 2519 (2019).

53 Pettersen, E. F. et al. UCSF Chimera--a visualization system for exploratory research and analysis. J Comput Chem 25, 1605-1612 (2004).

54 Goddard, T. D. et al. UCSF ChimeraX: Meeting modern challenges in visualization and analysis. Protein Sci 27, 14-25 (2018).

55 Schrödinger, L. The PyMOL Molecular Graphics System, Version 1.8 (2015).

56 Bailey, M., Chettiath, T. \& Mankin, A. S. Induction of erm (C) expression by noninducing antibiotics. Antimicrobial agents and chemotherapy 52, 866-874 (2008).

57 Nakamura, Y., Gojobori, T. \& Ikemura, T. Codon usage tabulated from international DNA sequence databases: status for the year 2000. Nucleic Acids Res 28, 292 (2000). 
bioRxiv preprint doi: https://doi.org/10.1101/604074; this version posted November 25, 2019. The copyright holder for this preprint (which was not certified by peer review) is the author/funder, who has granted bioRxiv a license to display the preprint in perpetuity. It is made available under aCC-BY-NC-ND 4.0 International license.

\section{SUPPLEMENTARY INFORMATION}


bioRxiv preprint doi: https://doi.org/10.1101/604074; this version posted November 25, 2019. The copyright holder for this preprint (which was not certified by peer review) is the author/funder, who has granted bioRxiv a license to display the preprint in perpetuity. It is made available under aCC-BY-NC-ND 4.0 International license.

\section{Supplementary Figure 1}

a

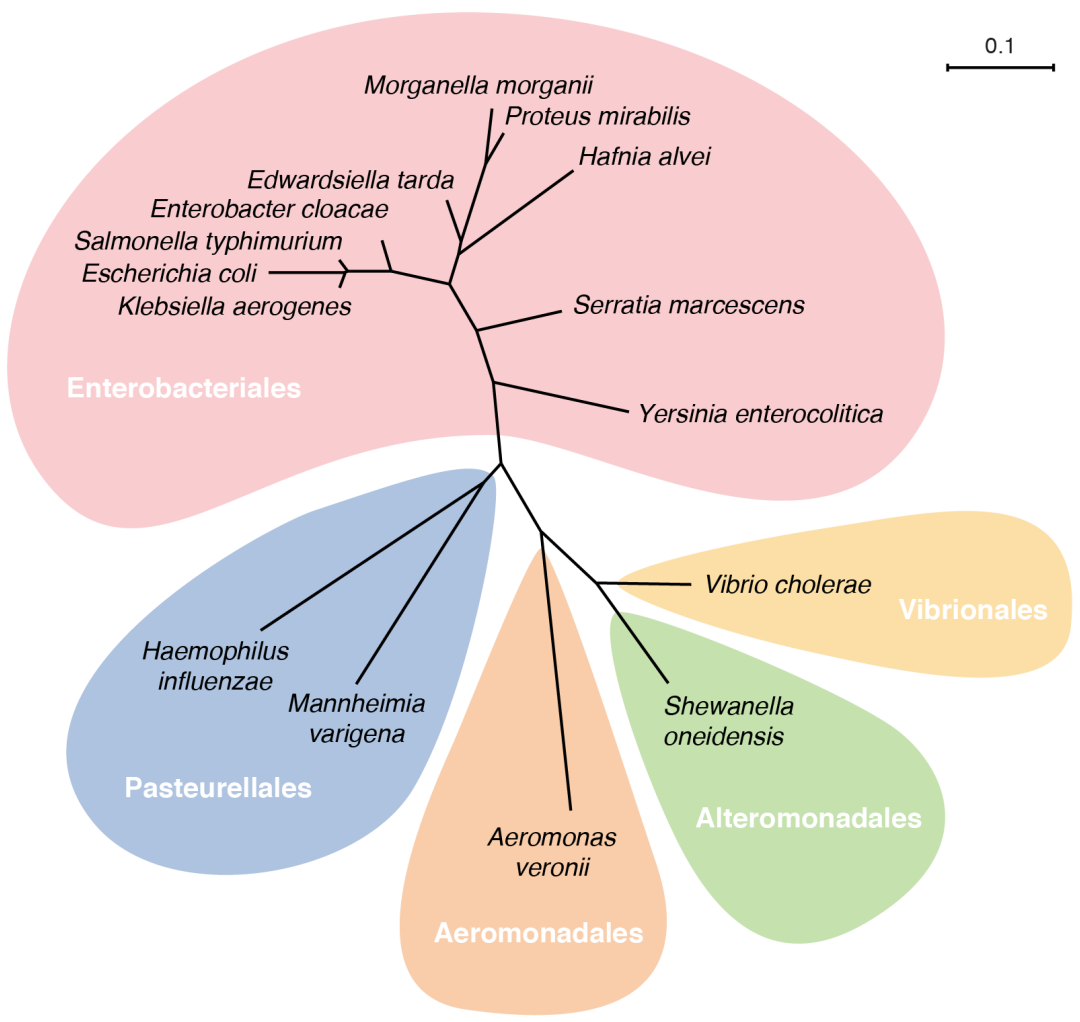

b

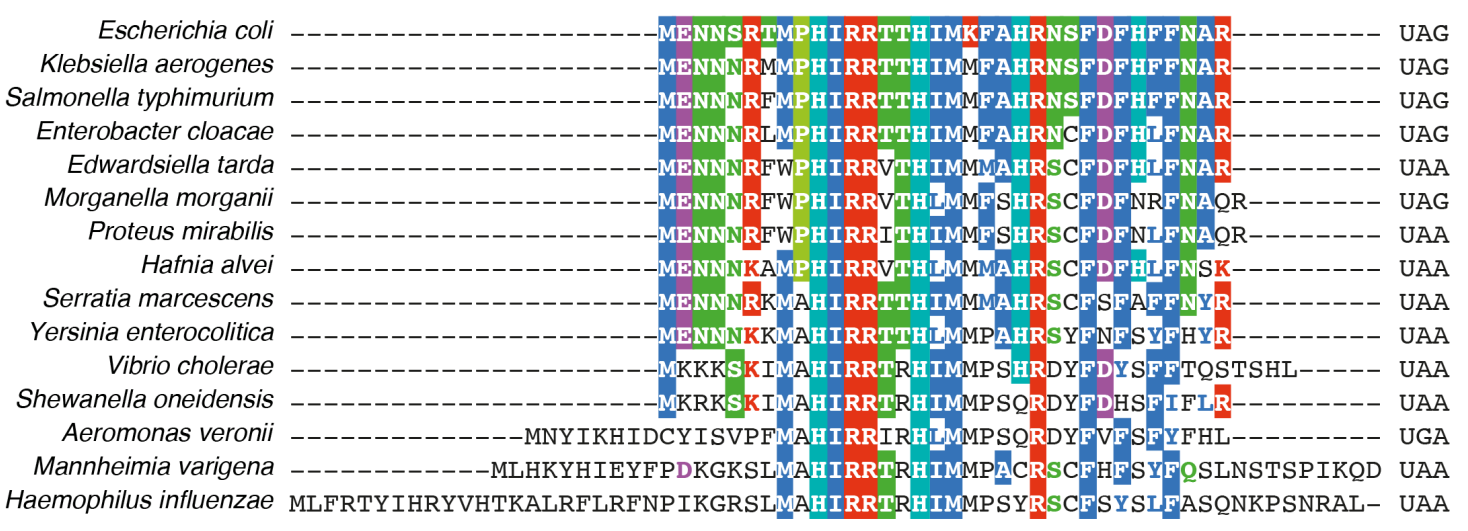

Supplementary Figure 1 | Conservation of SpeFL across $\gamma$-proteobacteria. a, Phylogenetic tree showing the distribution of representative speFL sequences from several orders of $\gamma$ proteobacteria. b. Multiple sequence alignment of SpeFL homologs from different species. The sequence shown for Salmonella typhimurium corresponds to the previously reported orf34 ${ }^{1}$. SpeFL and its homologs belong to the group of proteins of unknown function DUF $2618^{2}$. The stop codon found after each sequence is indicated on the right of the alignment. 
bioRxiv preprint doi: https://doi.org/10.1101/604074; this version posted November 25, 2019. The copyright holder for this preprint (which was not certified by peer review) is the author/funder, who has granted bioRxiv a license to display the preprint in perpetuity. It is made available under aCC-BY-NC-ND 4.0 International license.

\section{Supplementary Figure 2}

Ornithine

$\begin{array}{llllllllll}0 & 0.1 & 0.25 & 0.5 & 1 & 2.5 & 5 & 10 & 25 & \mathrm{mM}\end{array}$

C U A G

RBS speFL $\begin{gathered}75 \mathrm{nt} \\ \text { intergenic } \\ \text { region }\end{gathered}$
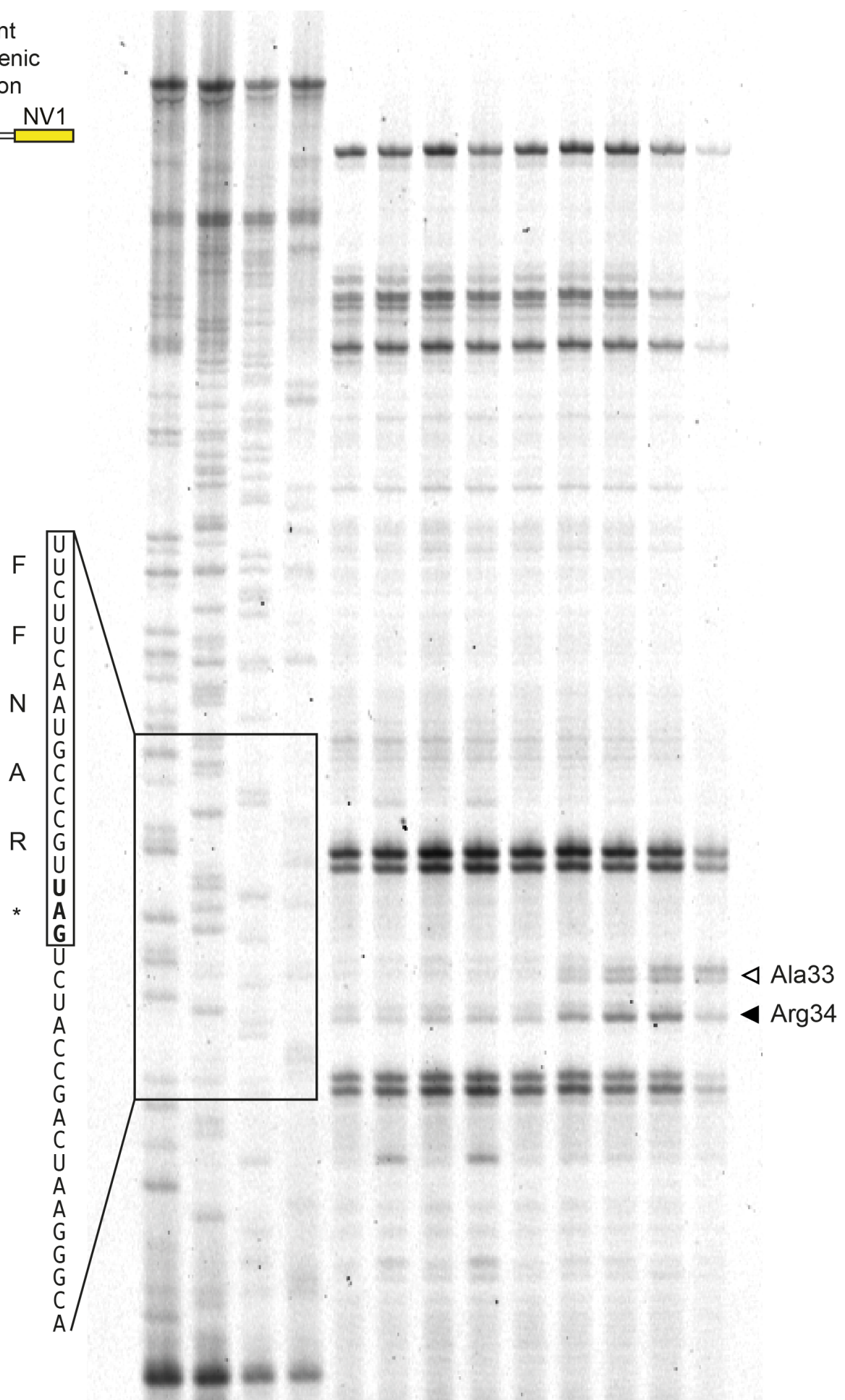
bioRxiv preprint doi: https://doi.org/10.1101/604074; this version posted November 25,2019 . The copyright holder for this preprint (which

was not certified by peer review) is the author/funder, who has granted bioRxiv a license to display the preprint in perpetuity. It is made available under aCC-BY-NC-ND 4.0 International license.

Supplementary Figure 2 | Dose-dependence of ornithine-mediated ribosome stalling on speFL. Toeprinting assay ${ }^{3,4}$ to monitor the translation of wild type speFL in the presence of increasing concentrations of ornithine. All samples were treated with $90 \mu \mathrm{M}$ puromycin. Arrows indicate ribosomes stalled with the codon for the indicated amino acid in the P-site (Ala33 - open triangle; Arg34 - filled triangle). A schematic representation of the DNA template used for toeprinting is provided (RBS - ribosome binding site; $N V 1^{5}$ - sequence used to anneal the Yakima Yellow-labeled probe for reverse transcription). 


\section{Supplementary Figure 3}

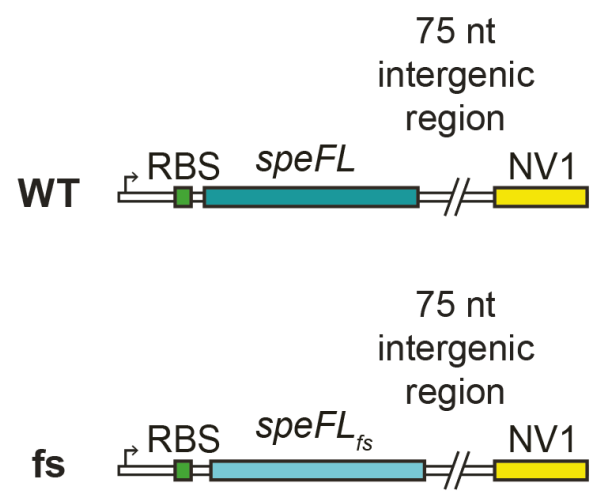

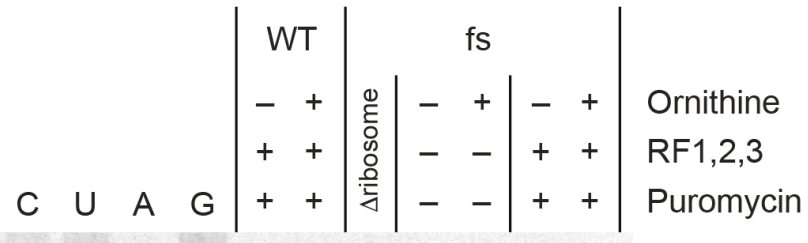

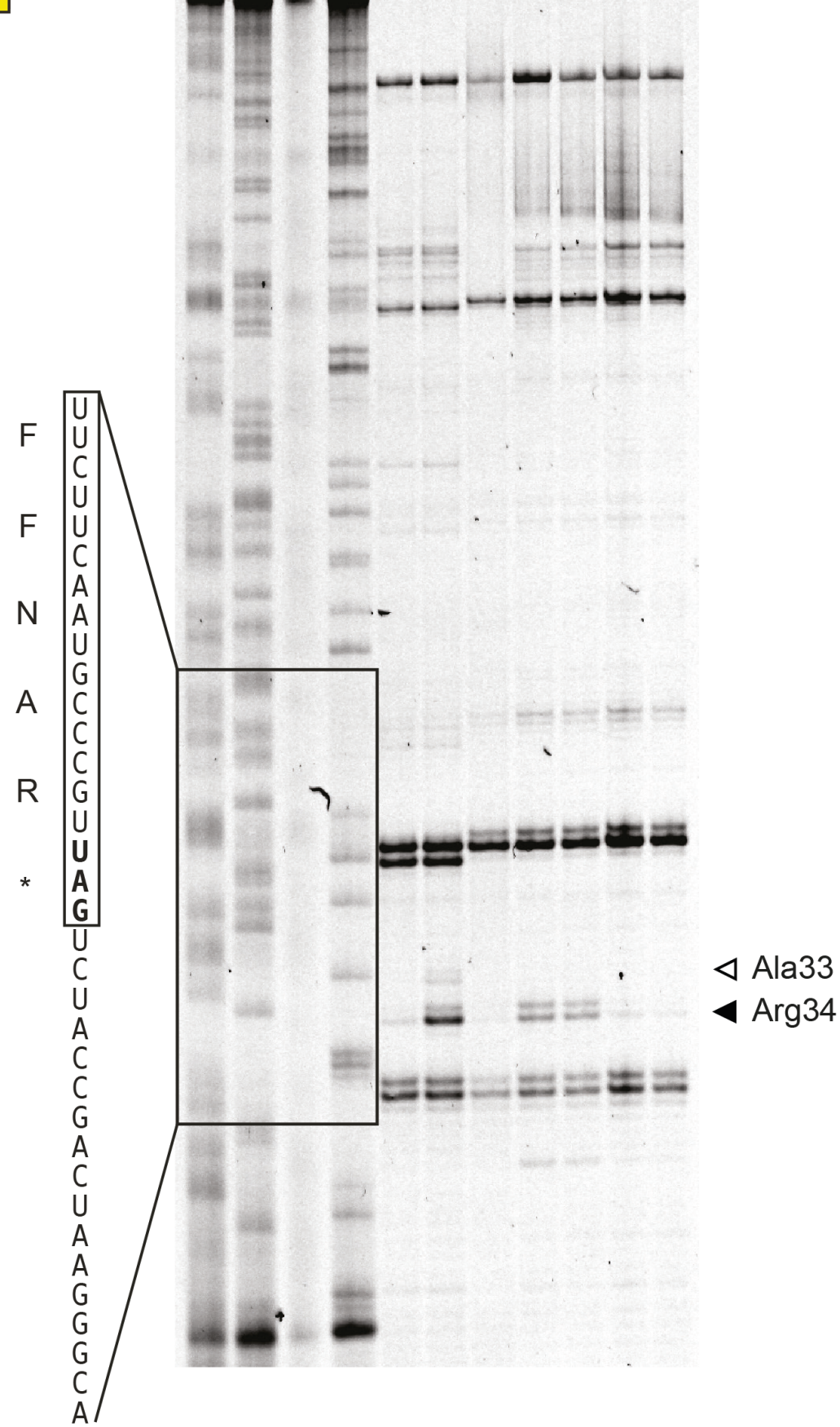


Supplementary Figure 3 | The amino acid sequence of SpeFL is important for ornithinedependent translational arrest. Toeprinting assay ${ }^{3,4}$ to monitor the translation of wild type (WT) and double frameshifted $\left(f_{s}\right)$ speFL in the presence $(+)$ or absence $(-)$ of $10 \mathrm{mM}$ ornithine, release factors $(\mathrm{RF} 1,2,3)$ or $90 \mu \mathrm{M}$ puromycin. Arrows indicate ribosomes stalled with the codon for the indicated amino acid in the P-site (Ala33 - open triangle; Arg34 - filled triangle). Schematic representations of the DNA templates used for toeprinting are provided (RBS ribosome binding site; $N V 1^{5}$ - sequence used to anneal the Yakima Yellow-labeled probe for reverse transcription). 
bioRxiv preprint doi: https://doi.org/10.1101/604074; this version posted November 25, 2019. The copyright holder for this preprint (which

was not certified by peer review) is the author/funder, who has granted bioRxiv a license to display the preprint in perpetuity. It is made available under aCC-BY-NC-ND 4.0 International license.

\section{Supplementary Figure 4}

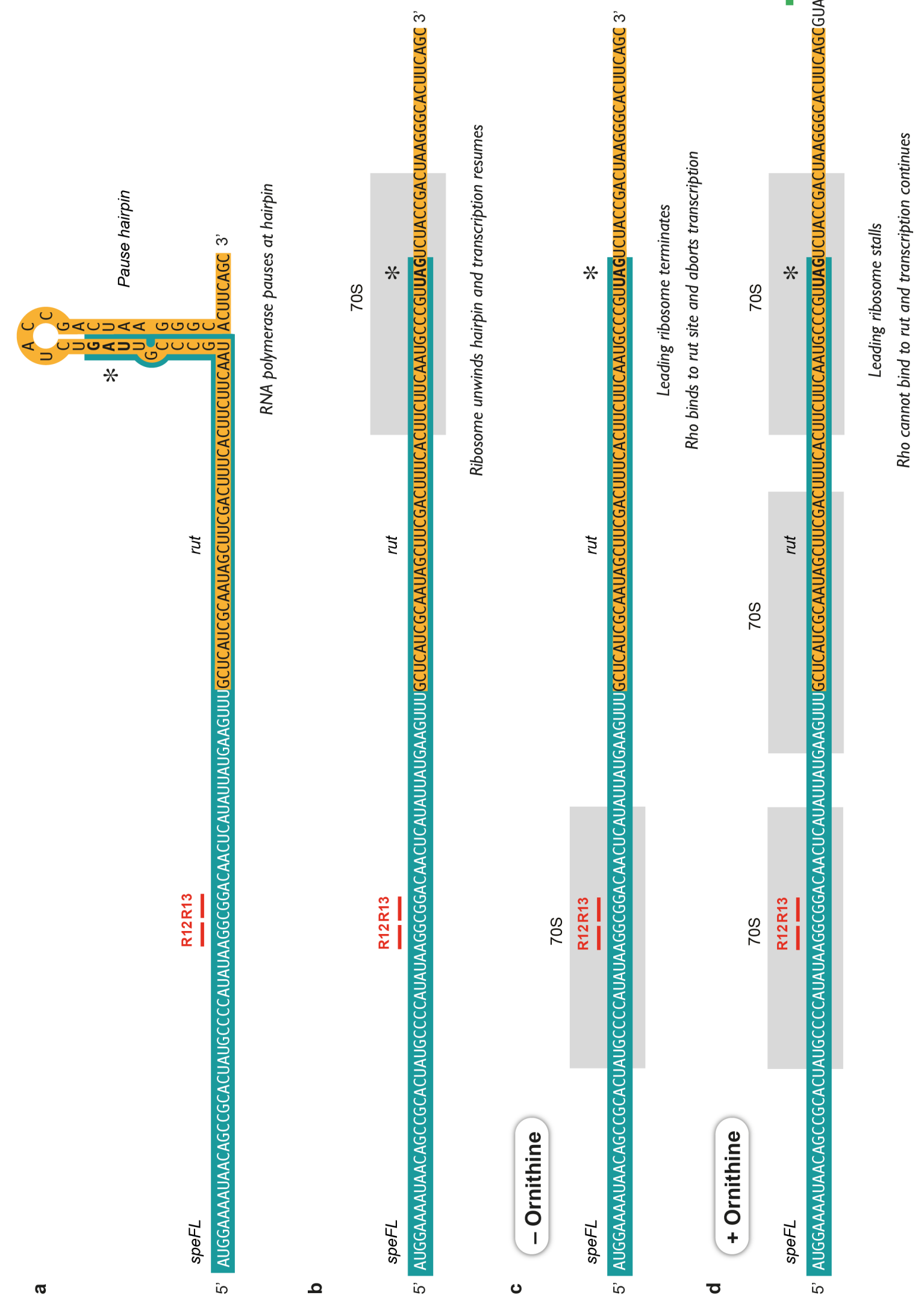


bioRxiv preprint doi: https://doi.org/10.1101/604074; this version posted November 25,2019 . The copyright holder for this preprint (which

was not certified by peer review) is the author/funder, who has granted bioRxiv a license to display the preprint in perpetuity. It is made available under aCC-BY-NC-ND 4.0 International license.

\section{Supplementary Figure 4 | Mechanism of the SpeFL- and Rho-dependent regulation of the speF} operon. The mRNA sequence of speFL and part of the adjacent intergenic region is shown at various stages of the induction process, namely (a) when the RNA polymerase pauses on a hairpin encompassing the $3^{\prime}$ end of $s p e F L$, (b) when the leading ribosome translating $s p e F L$ unwinds the pause hairpin, (c) when the leading ribosome terminates translation in the absence of ornithine to allow Rho to bind to the rut site and (d) when the leading ribosome stalls in the presence of ornithine and blocks Rho binding, allowing the operon to be transcribed. The footprints of the ribosomes are in gray, speFL is in turquoise, the rut site is in yellow, rare codons R12 and R13 are in red and the UAG stop codon is indicated with an asterisk. The predicted $3^{\prime}$ end of the premature transcript is at position -1 of the consensus pause-inducing sequence element $\mathrm{G}_{-11} \mathrm{G}_{-10}(\mathrm{C} / \mathrm{T})_{-1} \mathrm{G}_{+1}{ }^{6}$. 
bioRxiv preprint doi: https://doi.org/10.1101/604074; this version posted November 25, 2019. The copyright holder for this preprint (which was not certified by peer review) is the author/funder, who has granted bioRxiv a license to display the preprint in perpetuity. It is made available under aCC-BY-NC-ND 4.0 International license.

\section{Supplementary Figure 5}

a

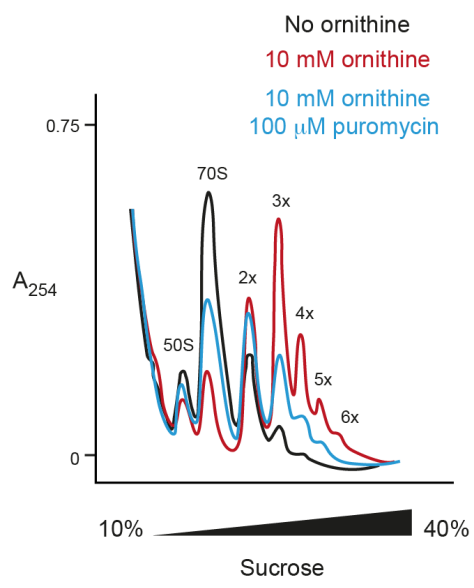

b

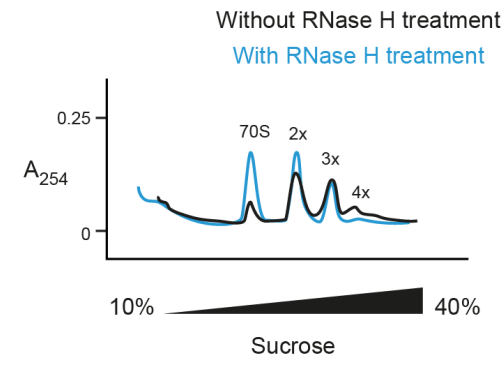

C

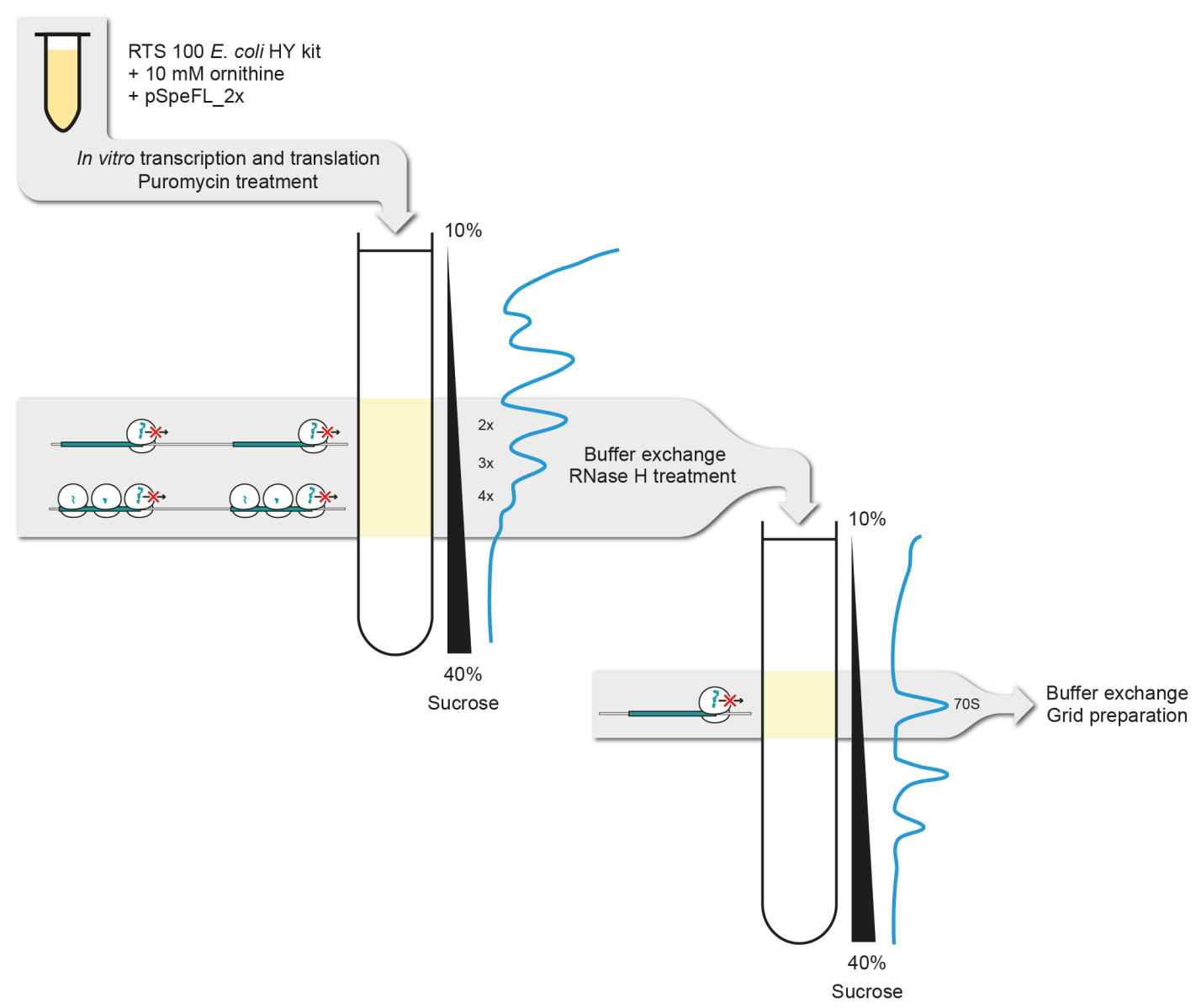

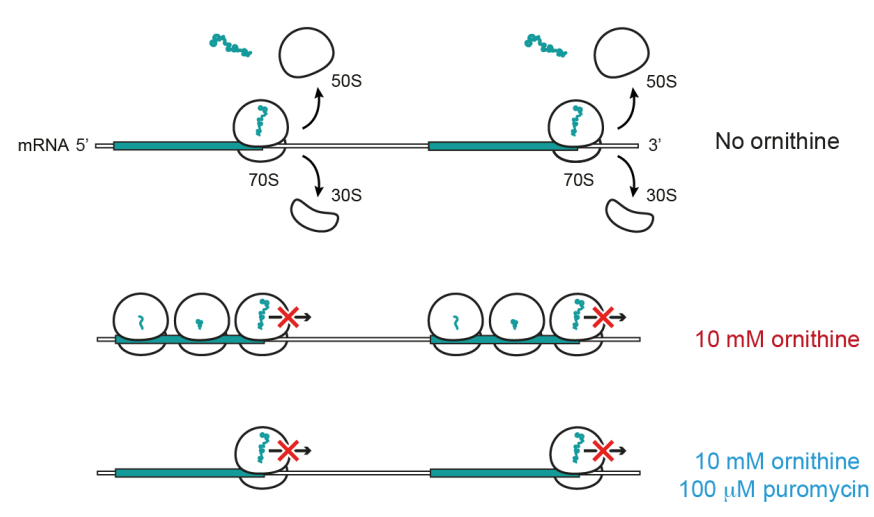

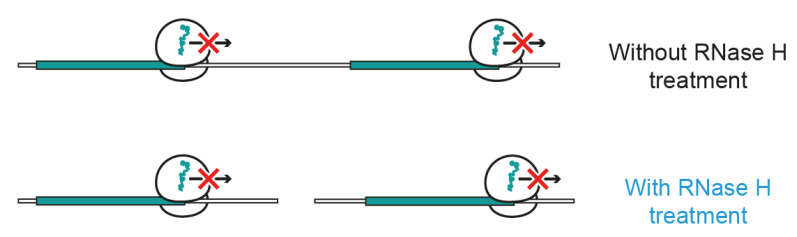

treatment 
Supplementary Figure 5 | Purification of a SpeFL-70S complex stalled in the presence of ornithine. a, Overlaid absorbance profiles of sucrose gradients containing a translation mixture incubated without ornithine (black), in the presence of $10 \mathrm{mM} \mathrm{L-ornithine} \mathrm{(red)} \mathrm{or} \mathrm{in} \mathrm{the}$ presence of $10 \mathrm{mM}$ L-ornithine followed by treatment with $100 \mu \mathrm{M}$ puromycin (blue). A schematic diagram depicting the expected ribosomal species in each fraction is shown on the right. b, Overlaid absorbance profiles of sucrose gradients loaded with polysomal fractions from a, with (blue) or without (black) RNase $\mathrm{H}$ treatment. Expected ribosomal species for each fraction are shown on the right. c, Schematic representation of the purification strategy for SpeFL-70S. The collected fractions are indicated with gray boxes. 


\section{Supplementary Figure 6}
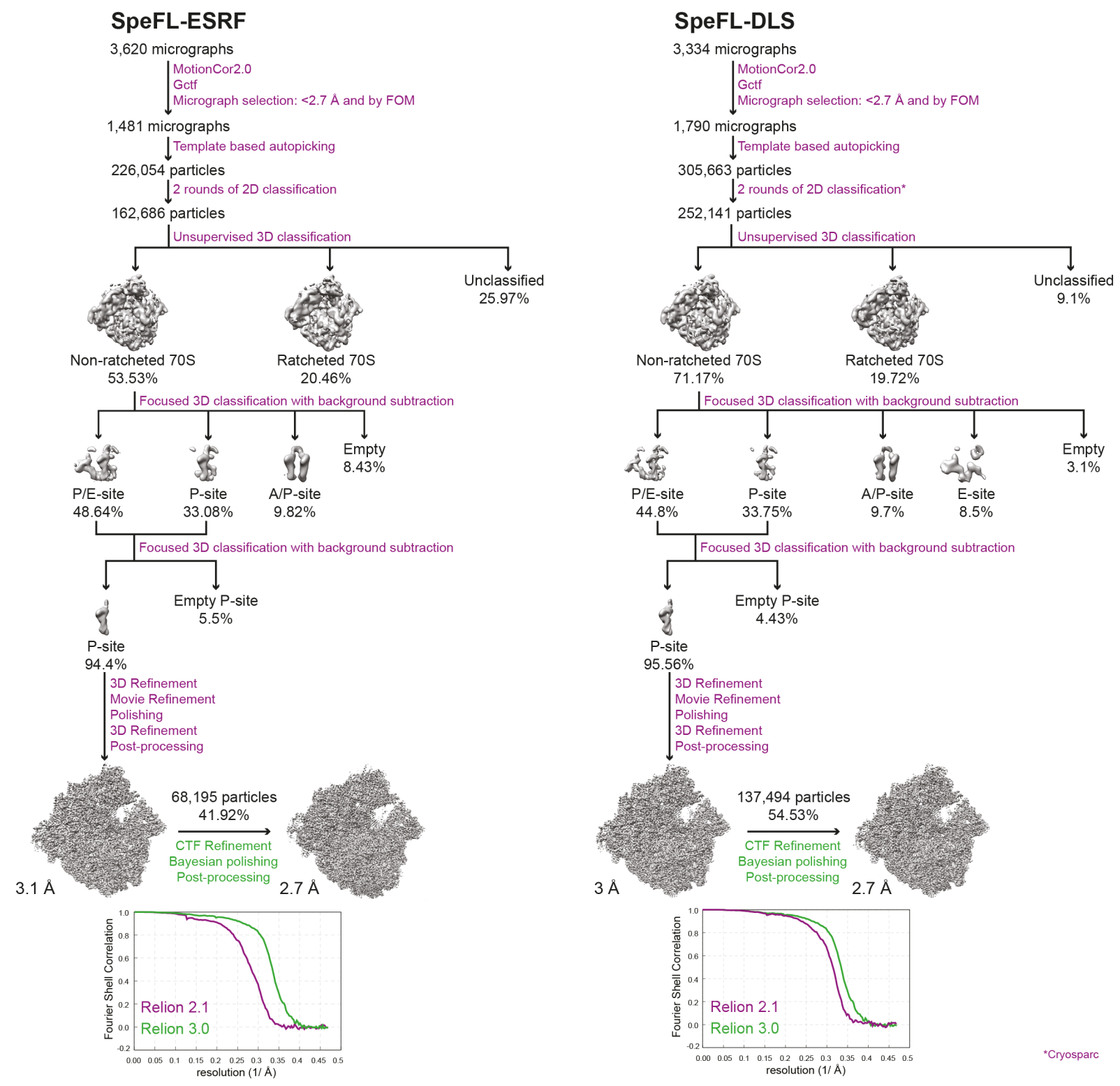

Supplementary Figure 6 | Flowchart of cryo-EM data processing for the SpeFL-ESRF and SpeFL-DLS datasets. Steps where Relion $2.1^{7}$ and Relion 3.0 ${ }^{8}$ were used are shown in purple and green, respectively. The step where Cryosparc $0.6^{9}$ was used is indicated with an asterisk. Note the increase in resolution when using Relion 3.0 compared to Relion 2.1. This increase was also matched by the quality of the resulting cryo-EM density. Both structures could be refined to an overall resolution of $2.7 \AA$ using a Fourier shell correlation (FSC) cutoff of 0.143 . 


\section{Supplementary Figure 7}

a

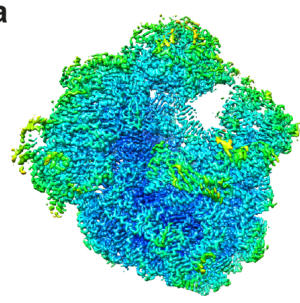

C

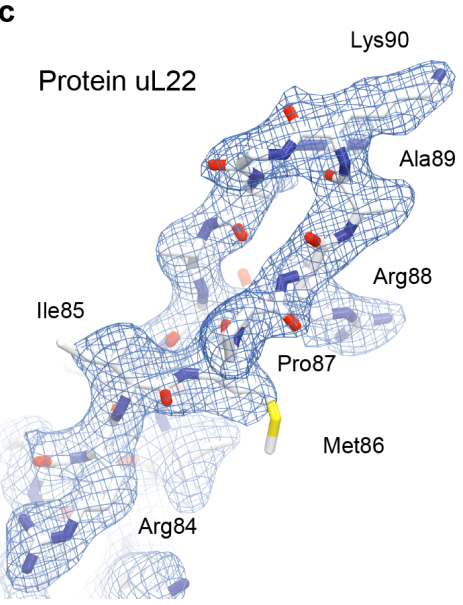

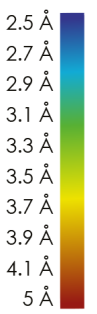
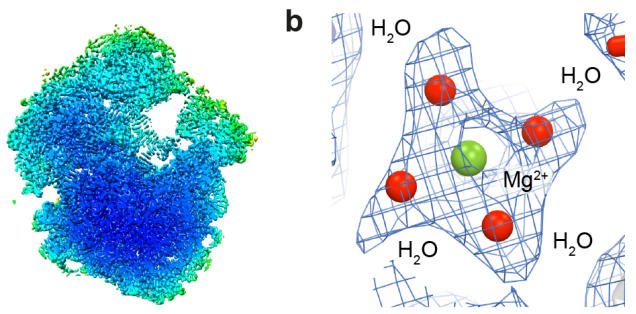

d

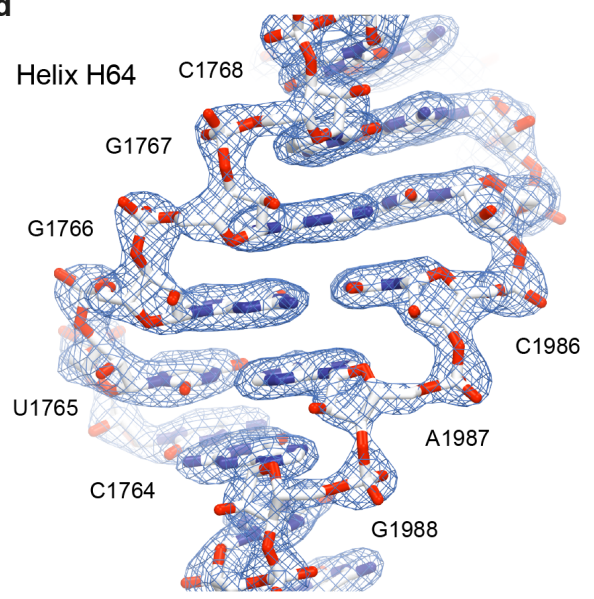

Supplementary Figure 7 | Quality of the cryo-EM reconstructions. a, Refined cryo-EM density map obtained in Relion $3.0^{8}$ filtered and colored by local resolution estimation values in Chimera $^{10}$. A cross-section of the same map is also shown. b,c,d, Representative cryo-EM densities for (b) a hydrated magnesium ion bound to the 23S rRNA, (c) the tunnel extension of ribosomal protein uL22 and (d) helix H64 of the 23S rRNA. 


\section{Supplementary Figure 8}
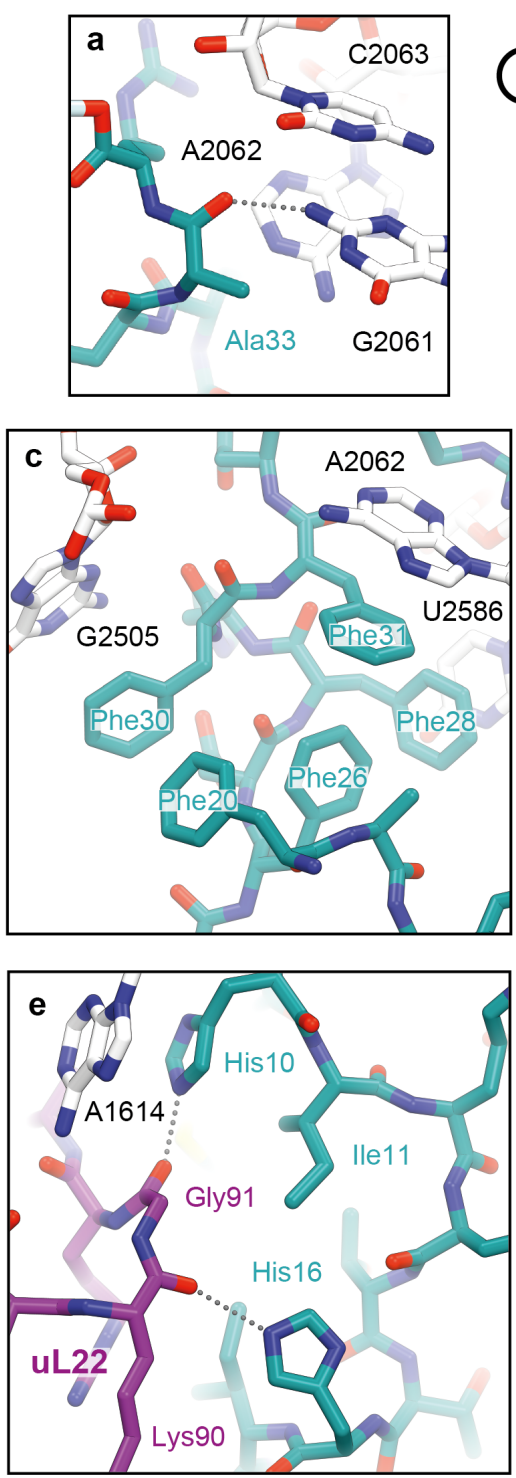
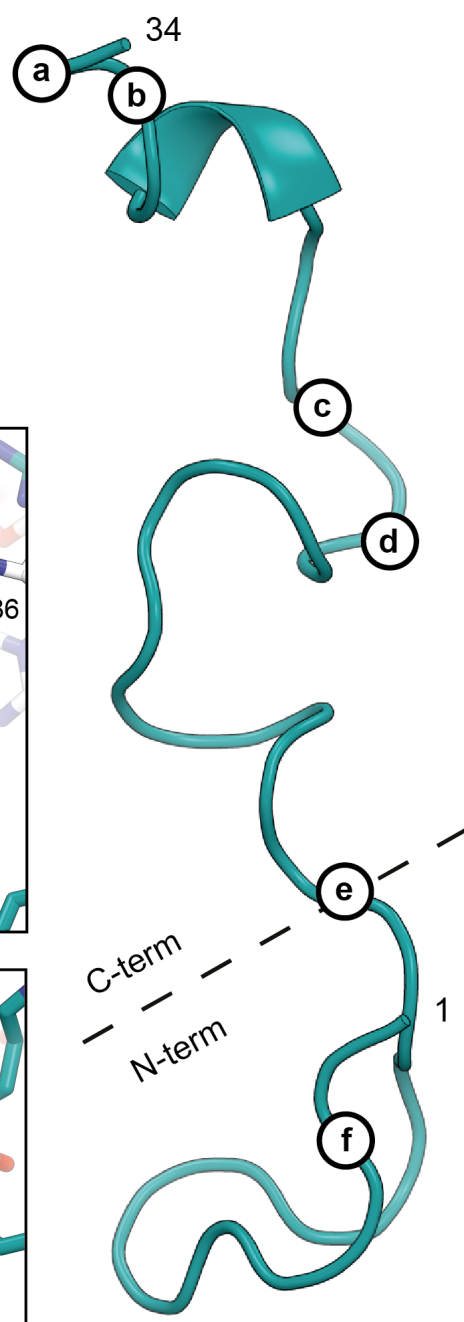
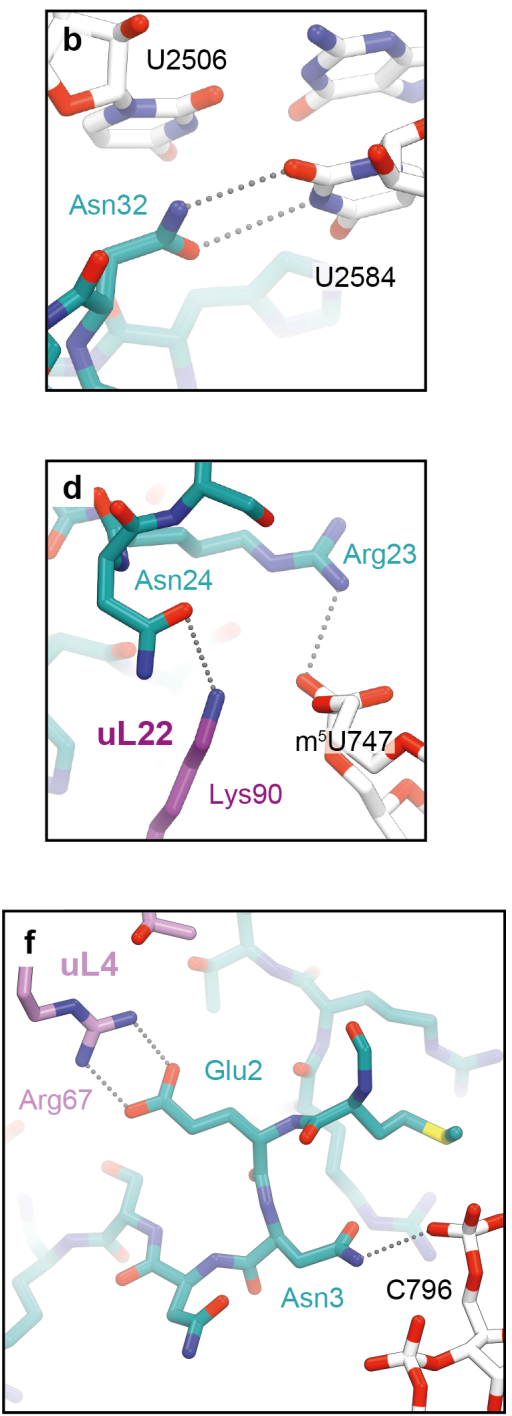

Supplementary Figure $8 \mid$ Interactions between SpeFL and the ribosome. A cartoon representation of SpeFL (turquoise) is shown in the middle panel. a, Potential hydrogen bond between Ala33 of SpeFL and the base of 23S rRNA residue G2061. b, Potential hydrogen bonds between Asn32 of SpeFL and the base of $23 \mathrm{~S}$ rRNA residue U2584. c, Hydrophobic core of the SpeFL effector domain formed by residues Phe20, Phe26, Phe28, Phe30 and Phe31. Phe28, Phe30 and Phe31 of SpeFL form $\pi$-stacking interactions with the bases of $23 \mathrm{~S}$ rRNA residues U2586, G2505 and A2062, respectively. d, Potential hydrogen bonds between Asn24 of SpeFL and Lys90 of ribosomal protein uL22, and electrostatic interaction between Arg23 of SpeFL and the phosphate backbone of $23 \mathrm{~S}$ rRNA residue $\mathrm{m}^{5} \mathrm{U} 747$. e, The HIRRXXH ornithine-binding motif of SpeFL, showing potential hydrogen bonds between His10 and His16 of SpeFL, and Gly91 and Lys90 of ribosomal protein uL22, respectively. $\pi$-stacking interaction between $23 \mathrm{~S}$ rRNA residue A1614 and His10 of SpeFL. f, Electrostatic interactions between residue Glu2 of SpeFL and residues Arg67 of ribosomal protein uL4. Possible hydrogen bond between residue Asn3 of SpeFL and the phosphate backbone of $23 \mathrm{~S}$ rRNA residue C796. 


\section{Supplementary Figure 9}
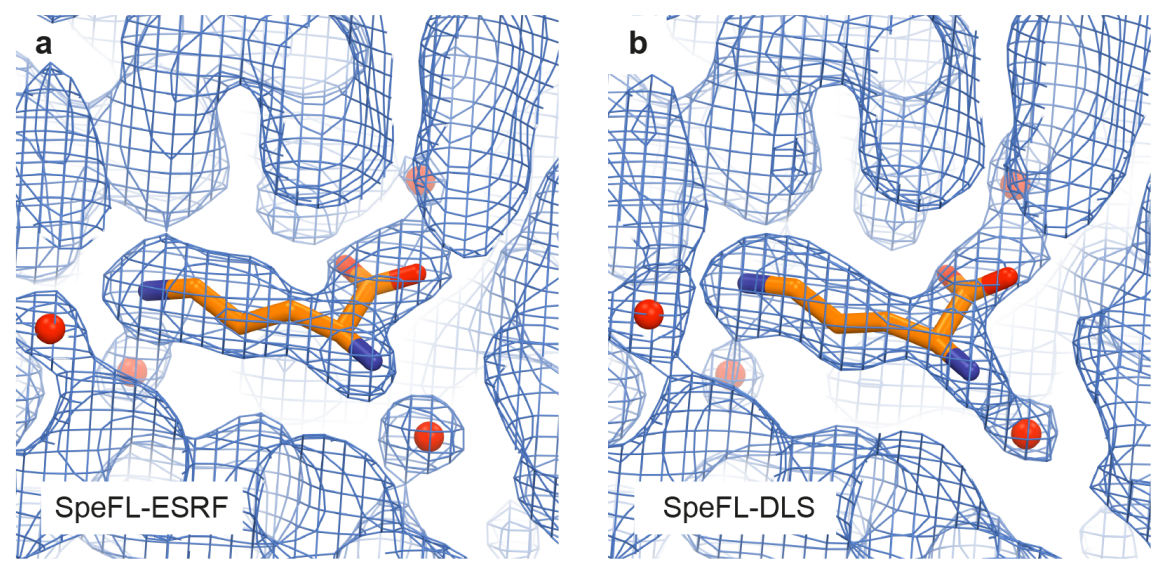

Supplementary Figure 9 | Sharpened cryo-EM density for L-ornithine and neighboring solvent molecules. A single L-ornithine molecule (orange) surrounded by 4 solvent molecules (red) is fitted into the cryo-EM density of the ligand binding pocket obtained for the (a) SpeFL-ESRF and (b) SpeFL-DLS datasets. Note that peaks for the solvent molecules are visible in the two independently determined cryo-EM maps, indicating that these densities cannot be attributed to random noise. 


\section{Supplementary Figure 10}

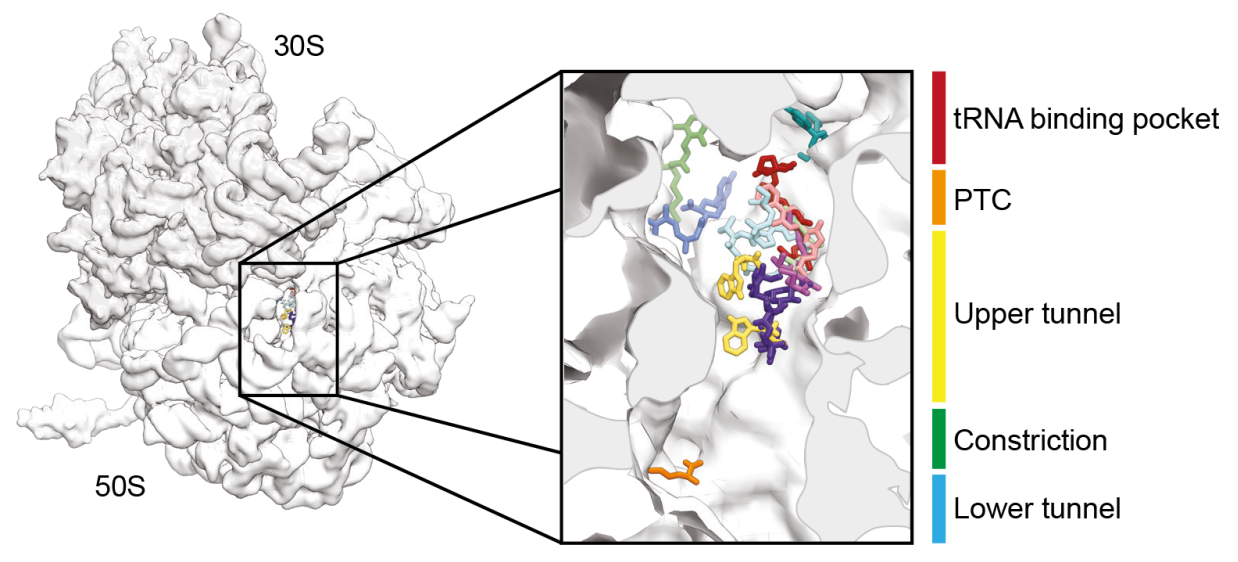

Supplementary Figure 10 | Small ligand binding pockets of the ribosomal exit tunnel. Overview and close-up view of a cross-section of the $E$. coli $70 S$ ribosomal exit tunnel showing the L-ornithine molecule observed in this work (orange) together with small molecules that are known to bind to the ribosomal exit tunnel: blasticin S (PDB: 4v9q, dark blue) ${ }^{11}$, chloramphenicol (PDB: $4 \mathrm{v} 7 \mathrm{w}$, light green) ${ }^{12}$, clindamycin (PDB: $4 \mathrm{v} 7 \mathrm{v}$, magenta) ${ }^{13}$, dalfopristin (PDB: 4u24, light blue) ${ }^{14}$, erythromycin (PDB: 4v7u, purple) ${ }^{13}$, hygromycin (PDB: 5 dox, red) ${ }^{15}$, linezolid (PDB: 3dll, pink) ${ }^{16}$, puromycin (PDB: 1q82, cyan) ${ }^{17}$, sparsomycin (PDB: 1 njn, dark

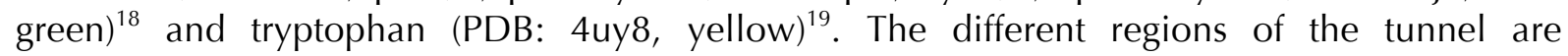
highlighted: the tRNA binding pocket (red), the peptidyl transferase center (PTC) (orange), the upper tunnel (yellow), the constriction formed by uL22 and uL4 (green) and the lower tunnel (blue). 
bioRxiv preprint doi: https://doi.org/10.1101/604074; this version posted November 25, 2019. The copyright holder for this preprint (which was not certified by peer review) is the author/funder, who has granted bioRxiv a license to display the preprint in perpetuity. It is made available under aCC-BY-NC-ND 4.0 International license.

\section{Supplementary Figure 11}

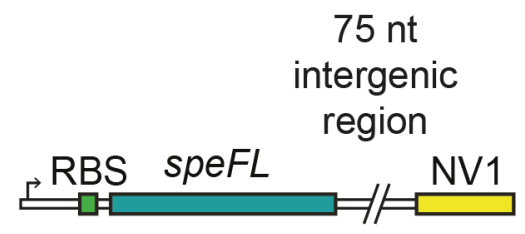

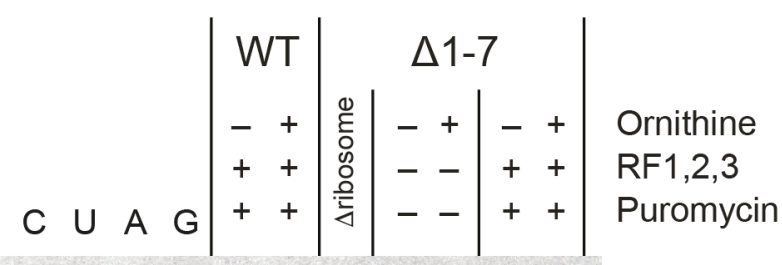

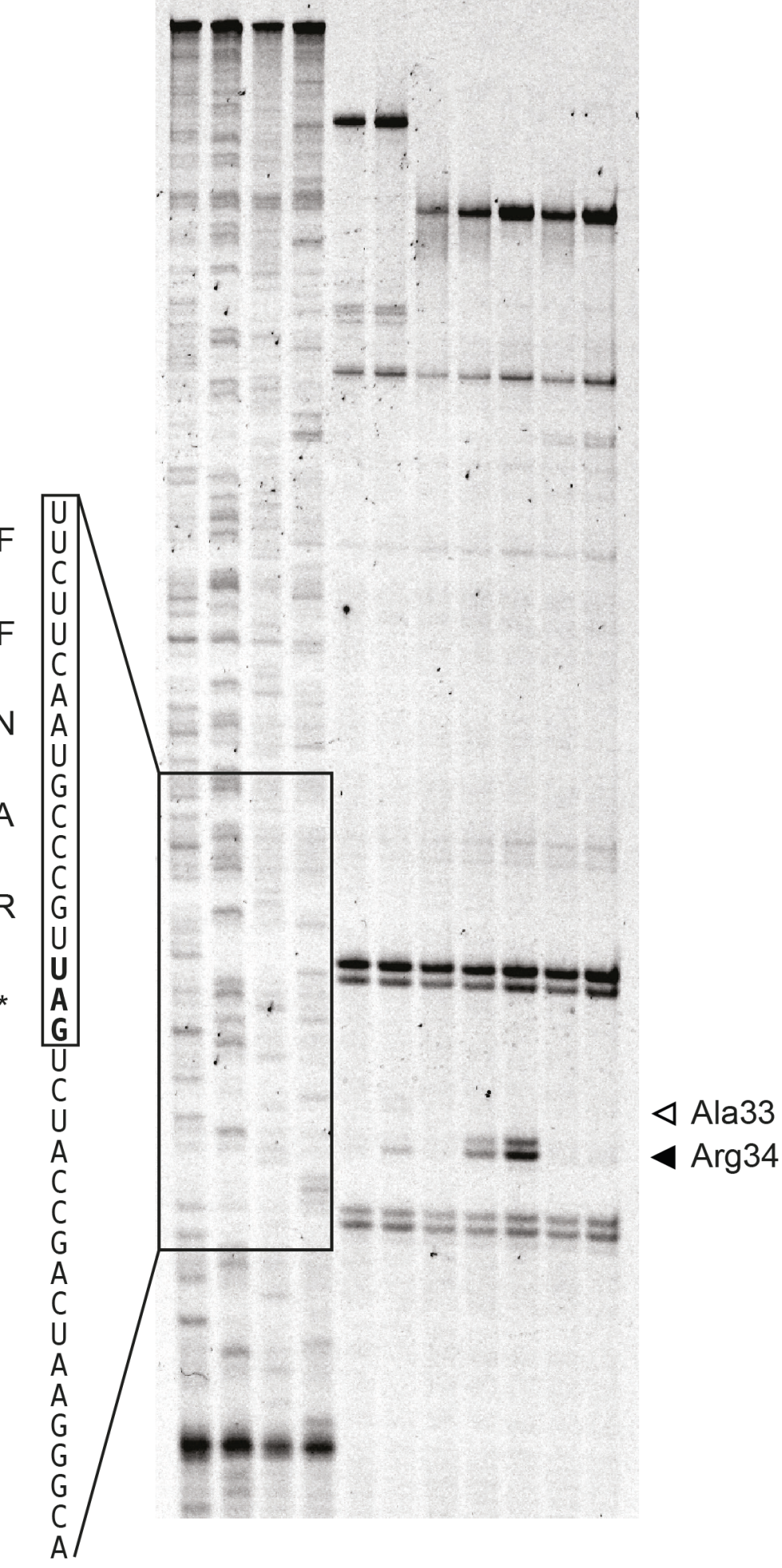

$\mathrm{N}$

A

A


Supplementary Figure 11 | Importance of residues 1-7of SpeFL. Toeprinting assay, to monitor the translation of wild-type speFL and speFL $\Delta 1-7$ in the absence (-) or presence (+) of $10 \mathrm{mM}$ ornithine, release factors $(\mathrm{RF} 1,2,3)$ or $90 \mu \mathrm{M}$ puromycin. Arrows indicate ribosomes stalled with the indicated amino acid in the P-site (Ala33 - open triangle; Arg34 - filled triangle). A schematic representation of the DNA template used for toeprinting is provided (RBS - ribosome binding site; $N V 1^{5}$ - sequence used to anneal the Yakima Yellow-labeled probe for reverse transcription). 
bioRxiv preprint doi: https://doi.org/10.1101/604074; this version posted November 25, 2019. The copyright holder for this preprint (which was not certified by peer review) is the author/funder, who has granted bioRxiv a license to display the preprint in perpetuity. It is made available under aCC-BY-NC-ND 4.0 International license.

\section{Supplementary Figure 12}

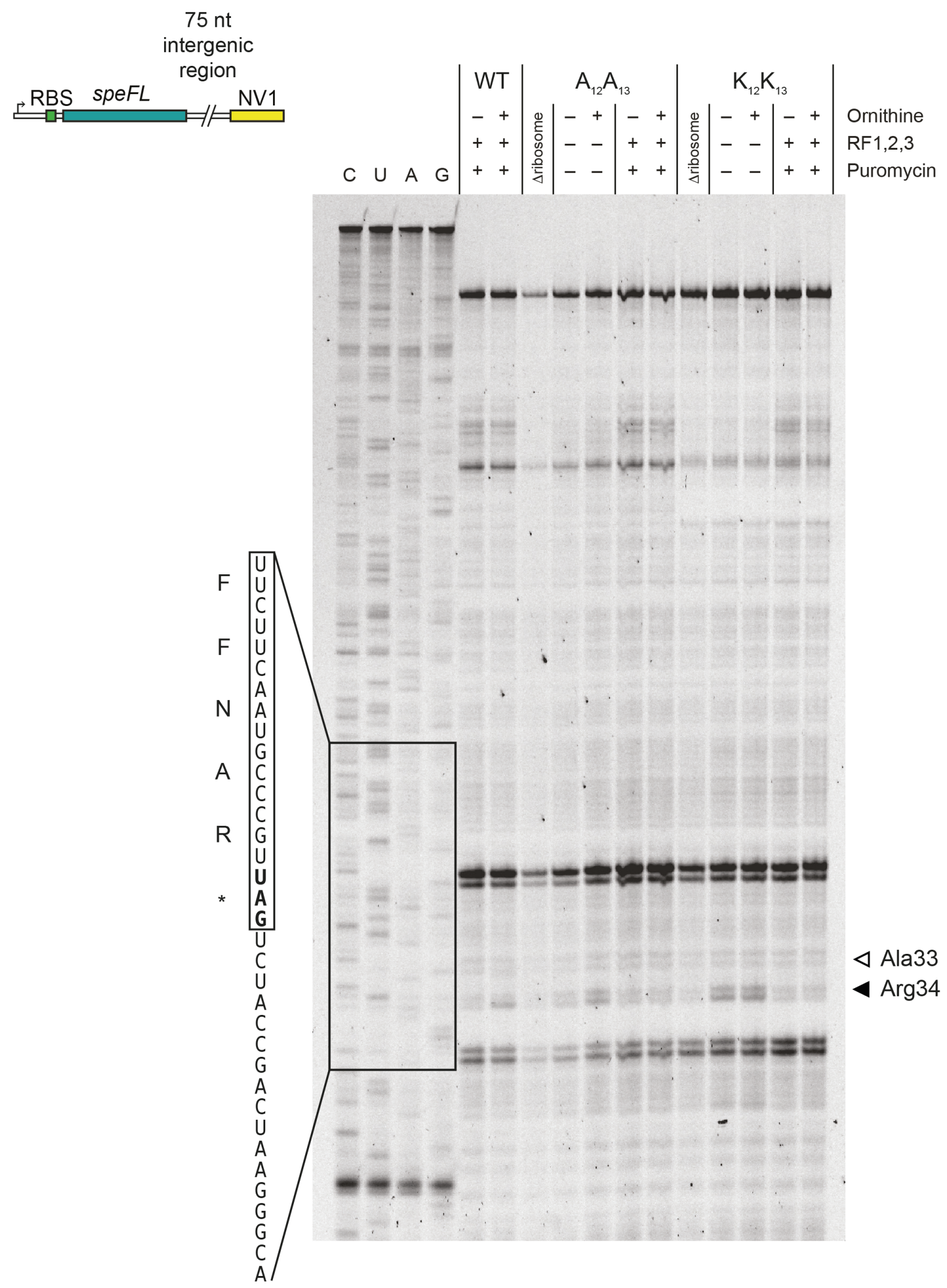


bioRxiv preprint doi: https://doi.org/10.1101/604074; this version posted November 25, 2019. The copyright holder for this preprint (which

was not certified by peer review) is the author/funder, who has granted bioRxiv a license to display the preprint in perpetuity. It is made available under aCC-BY-NC-ND 4.0 International license.

Supplementary Figure 12 | Importance of residues 12 and 13 of SpeFL. Toeprinting assay $y^{3,4}$ to monitor the translation of wild-type speFL, speFL-R12A-R13A $\left(\mathrm{A}_{12} \mathrm{~A}_{13}\right)$ and speFL-R12K-R13K $\left(\mathrm{K}_{12} \mathrm{~K}_{13}\right)$ in the absence $(-)$ or presence $(+)$ of $10 \mathrm{mM}$ ornithine, release factors (RF1,2,3) or 90 $\mu \mathrm{M}$ puromycin. Arrows indicate ribosomes stalled with the indicated amino acid in the P-site (Ala33 - open triangle; Arg34 - filled triangle). A schematic representation of the DNA template used for toeprinting is provided (RBS - ribosome binding site; $N V 1^{5}$ - sequence used to anneal the Yakima Yellow-labeled probe for reverse transcription). 
bioRxiv preprint doi: https://doi.org/10.1101/604074; this version posted November 25, 2019. The copyright holder for this preprint (which was not certified by peer review) is the author/funder, who has granted bioRxiv a license to display the preprint in perpetuity. It is made available under aCC-BY-NC-ND 4.0 International license.

\section{Supplementary Figure 13}

$75 \mathrm{nt}$

intergenic

region

RBS speFL NV1

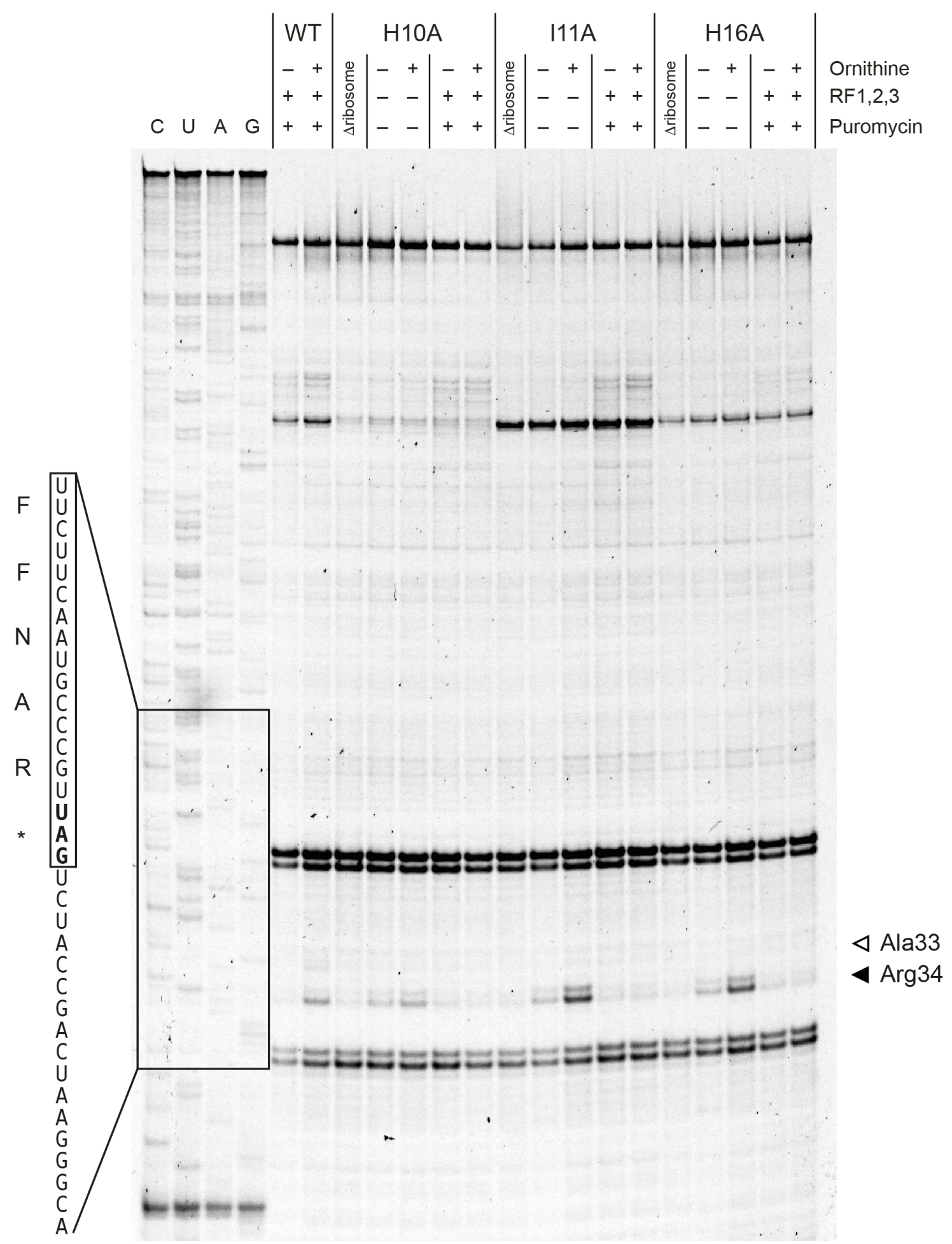


bioRxiv preprint doi: https://doi.org/10.1101/604074; this version posted November 25, 2019. The copyright holder for this preprint (which

was not certified by peer review) is the author/funder, who has granted bioRxiv a license to display the preprint in perpetuity. It is made available under aCC-BY-NC-ND 4.0 International license.

Supplementary Figure 13 | Importance of residues 10, 11 and 16 of SpeFL. Toeprinting assay $^{3,4}$ to monitor the translation of wild-type speFL, speFL-H10A, speFL-111A and speFL-H16A in the absence $(-)$ or presence $(+)$ of $10 \mathrm{mM}$ ornithine, release factors (RF1,2,3) or $90 \mu \mathrm{M}$ puromycin. Arrows indicate ribosomes stalled with the indicated amino acid in the P-site (Ala33 - open triangle; Arg34 - filled triangle). A schematic representation of the DNA template used for toeprinting is provided (RBS - ribosome binding site; $N V 1^{5}$ - sequence used to anneal the Yakima Yellow-labeled probe for reverse transcription). 


\section{Supplementary Table 1 | Oligonucleotides}

\begin{tabular}{|c|c|c|}
\hline Number & Name & Sequence \\
\hline 1 & T7_RBS_ATG_f & $\begin{array}{l}\text { CGA-TCG-AAT-TCT-AAT-ACG-ACT-CAC- } \\
\text { TAT-AGG-GCT-TAA-GTA-TAA-GGA-GGA- } \\
\text { AAA-AAT-ATG }\end{array}$ \\
\hline 2 & TP_SpeFL_WT_f & $\begin{array}{l}\text { GGA-GGA-AAA-AAT-ATG-GAA-AAT-AAC- } \\
\text { AGC-CGC-ACT-ATG-CCC-CAT-ATA-AGG- } \\
\text { CGG-ACA-ACT }\end{array}$ \\
\hline 3 & TP_speFL_NV_r & $\begin{array}{l}\text { GGT-TAT-AAT-GAA-TTT-TGC-TTA-TTA- } \\
\text { ACT-GCG-GAA-TAC-AGG-CAT-ATG-CCT- } \\
\text { GTA-ATA-CA }\end{array}$ \\
\hline 4 & T7_f & $\begin{array}{l}\text { CGA-TCG-AAT-TCT-AAT-ACG-ACT-CAC- } \\
\text { TAT-AG }\end{array}$ \\
\hline 5 & TP_NV1_r & GGT-TAT-AAT-GAA-TTT-TGC-TTA-TT \\
\hline 6 & TP_speFL_M1-7_f & $\begin{array}{l}\text { GGA-GGA-AAA-AAT-ATG-CCC-CAT-ATA- } \\
\text { AGG-CGG-ACA-ACT }\end{array}$ \\
\hline 7 & pZa_speFL_WT_f & $\begin{array}{l}\text { CTA-GTC-TTA-ATT-AAG-TCT-TAT-AAG- } \\
\text { GAG-GAA-AAC-ATA-TGG-AAA-ATA-ACA- } \\
\text { GCC-G }\end{array}$ \\
\hline 8 & pZa_speFL_WT_r & $\begin{array}{l}\text { CGA-CGT-TGT-AAA-ACG-ACG-GCC-AGT- } \\
\text { GAA-TCC-TTT-TTT-GAC-ATT-TTT-CAT- } \\
\text { CTC-TTT-A }\end{array}$ \\
\hline 9 & pZa_f & $\begin{array}{l}\text { GTG-GTT-ATA-ATG-AAT-CGT-TAA-TAA- } \\
\text { G }\end{array}$ \\
\hline 10 & pZa_r & $\begin{array}{l}\text { ATG-TTT-TCC-TCC-TTA-TAA-GAC-TTA- } \\
\text { ATT-AAG }\end{array}$ \\
\hline 11 & pZa_SpeFL R12 ${ }_{c} R 13_{r-f}$ & $\begin{array}{l}\text { CGT-CGG-ACA-ACT-CAT-ATT-ATG-AAG- } \\
\text { TTT-GCT-CAT-CGC-AAT-AGC }\end{array}$ \\
\hline 12 & pZa_SpeFL R12,R13 cf & $\begin{array}{l}\text { AGG-CGT-ACA-ACT-CAT-ATT-ATG-AAG- } \\
\text { TTT-GCT-CAT-CGC-AAT-AGC }\end{array}$ \\
\hline 13 & pZa_SpeFL R12_R13 ${ }_{c-} f$ & $\begin{array}{l}\text { CGT-CGT-ACA-ACT-CAT-ATT-ATG-AAG- } \\
\text { TTT-GCT-CAT-CGC-AAT-AGC }\end{array}$ \\
\hline 14 & pZa_SpeFL_R12R13_mut_r & $\begin{array}{l}\text { TAT-ATG-GGG-CAT-AGT-GCG-GCT-GTT- } \\
\text { АTT }\end{array}$ \\
\hline 15 & rnaseH & ССТ-ССТ-ТАТ-АAA-АCT \\
\hline
\end{tabular}




\section{Supplementary Table 2 | DNA templates}

\begin{tabular}{|c|c|}
\hline Name & Sequence \\
\hline TP_SpeFL_WT & $\begin{array}{l}\text { CGA-TCG-AAT-TCT-AAT-ACG-ACT-CAC-TAT-AGG-GCT-TAA- } \\
\text { GTA-TAA-GGA-GGA-AAA-AAT-ATG-GAA-AAT-AAC-AGC-CGC- } \\
\text { ACT-ATG-CCC-CAT-ATA-AGG-CGG-ACA-ACT-CAT-ATT-ATG- } \\
\text { AAG-TTT-GCT-CAT-CGC-AAT-AGC-TTC-GAC-TTT-CAC-TTC- } \\
\text { TTC-AAT-GCC-CGT-TAG-TCT-ACC-GAC-TAA-GGG-CAC-TTC- } \\
\text { AGC-GTA-CAG-GTC-TTC-CTG-ACT-CTC-TGT-ATT-ACA-GGC- } \\
\text { ATA-TGC-CTG-TAT-TCC-GCA-GTT-AAT-AAG-CAA-AAT-TCA- } \\
\text { TTA-TAA-CC }\end{array}$ \\
\hline TP_SpeFL_M1-7 & $\begin{array}{l}\text { CGA-TCG-AAT-TCT-AAT-ACG-ACT-CAC-TAT-AGG-GCT-TAA- } \\
\text { GTA-TAA-GGA-GGA-AAA-AAT-ATG-CCC-CAT-ATA-AGG-CGG- } \\
\text { ACA-ACT-CAT-ATT-ATG-AAG-TTT-GCT-CAT-CGC-AAT-AGC- } \\
\text { TTC-GAC-TTT-CAC-TTC-TTC-AAT-GCC-CGT-TAG-TCT-ACC- } \\
\text { GAC-TAA-GGG-CAC-TTC-AGC-GTA-CAG-GTC-TTC-CTG-ACT- } \\
\text { CTC-TGT-ATT-ACA-GGC-ATA-TGC-CTG-TAT-TCC-GCA-GTT- } \\
\text { AAT-AAG-CAA-AAT-TCA-TTA-TAA-CC }\end{array}$ \\
\hline TP_SpeFL_fs & $\begin{array}{l}\text { CGA-TCG-AAT-TCT-AAT-ACG-ACT-CAC-TAT-AGG-GCT-TAA- } \\
\text { GTA-TAA-GGA-GGA-AAA-AAT-ATG-AAA-ATA-ACA-GCC-GCA- } \\
\text { CTA-TGC-CCC-ATA-TCA-GGC-GGA-CAA-CTC-ATA-TTA-TCA- } \\
\text { AGT-TTG-CTC-ATC-GCA-ATA-GCT-TCG-ACT-TTC-ACT-TCT- } \\
\text { TCA-ATG-CCC-GTT-tAG-TCT-ACC-GAC-TAA-GGG-CAC-TTC- } \\
\text { AGC-GTA-CAG-GTC-TTC-CTG-ACT-CTC-TGT-ATT-ACA-GGC- } \\
\text { ATA-TGC-CTG-TAT-TCC-GCA-GTT-AAT-AAG-CAA-AAT-TCA- } \\
\text { TTA-TAA-CC }\end{array}$ \\
\hline TP_speFL_R12AR13A & $\begin{array}{l}\text { CGA-TCG-AAT-TCT-AAT-ACG-ACT-CAC-TAT-AGG-GCT-TAA- } \\
\text { GTA-TAA-GGA-GGA-AAA-AAT-ATG-GAA-AAT-AAC-AGC-CGC- } \\
\text { ACT-ATG-CCC-CAT-ATA-gC - - }- \text {-ACA-ACT-CAT-ATT-ATG- } \\
\text { AAG-TTT-GCT-CAT-CGC-AAT-AGC-TTC-GAC-TTT-CAC-TTC- } \\
\text { TTC-AAT-GCC-CGT-TAG-TCT-ACC-GAC-TAA-GGG-CAC-TTC- } \\
\text { AGC-GTA-CAG-GTC-TTC-CTG-ACT-CTC-TGT-ATT-ACA-GGC- } \\
\text { ATA-TGC-CTG-TAT-TCC-GCA-GTT-AAT-AAG-CAA-AAT-TCA- } \\
\text { TTA-TAA-CC }\end{array}$ \\
\hline TP_speFL_R12KR13K & $\begin{array}{l}\text { CGA-TCG-AAT-TCT-AAT-ACG-ACT-CAC-TAT-AGG-GCT-TAA- } \\
\text { GTA-TAA-GGA-GGA-AAA-AAT-ATG-GAA-AAT-AAC-AGC-CGC- } \\
\text { ACT-ATG-CCC-CAT-ATA-Aaa-aa-ACA-ACT-CAT-ATT-ATG- } \\
\text { AAG-TTT-GCT-CAT-CGC-AAT-AGC-TTC-GAC-TTT-CAC-TTC- } \\
\text { TTC-AAT-GCC-CGT-TAG-TCT-ACC-GAC-TAA-GGG-CAC-TTC- } \\
\text { AGC-GTA-CAG-GTC-TTC-CTG-ACT-CTC-TGT-ATT-ACA-GGC- } \\
\text { ATA-TGC-CTG-TAT-TCC-GCA-GTT-AAT-AAG-CAA-AAT-TCA- } \\
\text { TTA-TAA-CC }\end{array}$ \\
\hline TP_speFL_H10A & $\begin{array}{l}\text { CGA-TCG-AAT-TCT-AAT-ACG-ACT-CAC-TAT-AGG-GCT-TAA- } \\
\text { GTA-TAA-GGA-GGA-AAA-AAT-ATG-GAA-AAT-AAC-AGC-CGC- } \\
\text { ACT-ATG-CCC-gCg-ATA-AGG-CGG-ACA-ACT-CAT-ATT-ATG- } \\
\text { AAG-TTT-GCT-CAT-CGC-AAT-AGC-TTC-GAC-TTT-CAC-TTC- } \\
\text { TTC-AAT-GCC-CGT-TAG-TCT-ACC-GAC-TAA-GGG-CAC-TTC- } \\
\text { AGC-GTA-CAG-GTC-TTC-CTG-ACT-CTC-TGT-ATT-ACA-GGC- } \\
\text { ATA-TGC-CTG-TAT-TCC-GCA-GTT-AAT-AAG-CAA-AAT-TCA- } \\
\text { TTA-TAA-CC }\end{array}$ \\
\hline
\end{tabular}




\begin{tabular}{cl}
\hline Name & Sequence \\
\hline TP_speFL_I11A & CGA-TCG-AAT-TCT-AAT-ACG-ACT-CAC-TAT-AGG-GCT-TAA- \\
& GTA-TAA-GGA-GGA-AAA-AAT-ATG-GAA-AAT-AAC-AGC-CGC- \\
ACT-ATG-CCC-CAT-gCg-AGG-CGG-ACA-ACT-CAT-ATT-ATG- \\
AAG-TTT-GCT-CAT-CGC-AAT-AGC-TTC-GAC-TTT-CAC-TTC- \\
TTC-AAT-GCC-CGT-TAG-TCT-ACC-GAC-TAA-GGG-CAC-TTC- \\
AGC-GTA-CAG-GTC-TTC-CTG-ACT-CTC-TGT-ATT-ACA-GGC- \\
ATA-TGC-CTG-TAT-TCC-GCA-GTT-AAT-AAG-CAA-AAT-TCA- \\
TTA-TAA-CC \\
\hline TP_speFL_H16A \\
CGA-TCG-AAT-TCT-AAT-ACG-ACT-CAC-TAT-AGG-GCT-TAA- \\
& GTA-TAA-GGA-GGA-AAA-AAT-ATG-GAA-AAT-AAC-AGC-CGC- \\
& ACT-ATG-CCC-CAT-ATA-AGG-CGG-ACA-ACT-gC9-ATT-ATG- \\
& AAG-TTT-GCT-CAT-CGC-AAT-AGC-TTC-GAC-TTT-CAC-TTC- \\
& TTC-AAT-GCC-CGT-TAG-TCT-ACC-GAC-TAA-GGG-CAC-TTC- \\
& AGC-GTA-CAG-GTC-TTC-CTG-ACT-CTC-TGT-ATT-ACA-GGC- \\
& ATA-TGC-CTG-TAT-TCC-GCA-GTT-AAT-AAG-CAA-AAT-TCA- \\
\hline
\end{tabular}

TP_speFL_F26A

CGA-TCG-AAT-TCT-AAT-ACG-ACT-CAC-TAT-AGG-GCT-TAAGTA-TAA-GGA-GGA-AAA-AAT-ATG-GAA-AAT-AAC-AGC-CGCACT-ATG-CCC-CAT-ATA-AGG-CGG-ACA-ACT-CAT-ATT-ATGAAG-TTT-GCT-CAT-CGC-AAT-AGC-gCg-GAC-TTT-CAC-TTCTTC-AAT-GCC-CGT-TAG-TCT-ACC-GAC-TAA-GGG-CAC-TTCAGC-GTA-CAG-GTC-TTC-CTG-ACT-CTC-TGT-ATT-ACA-GGCATA-TGC-CTG-TAT-TCC-GCA-GTT-AAT-AAG-CAA-AAT-TCATTA-TAA-CC

TP_speFL_F28A

CGA-TCG-AAT-TCT-AAT-ACG-ACT-CAC-TAT-AGG-GCT-TAAGTA-TAA-GGA-GGA-AAA-AAT-ATG-GAA-AAT-AAC-AGC-CGCACT-ATG-CCC-CAT-ATA-AGG-CGG-ACA-ACT-CAT-ATT-ATGAAG-TTT-GCT-CAT-CGC-AAT-AGC-TTC-GAC-gCg-CAC-TTCTTC-AAT-GCC-CGT-TAG-TCT-ACC-GAC-TAA-GGG-CAC-TTCAGC-GTA-CAG-GTC-TTC-CTG-ACT-CTC-TGT-ATT-ACA-GGCATA-TGC-CTG-TAT-TCC-GCA-GTT-AAT-AAG-CAA-AAT-TCATTA-TAA-CC

TP_speFL_F30A

CGA-TCG-AAT-TCT-AAT-ACG-ACT-CAC-TAT-AGG-GCT-TAAGTA-TAA-GGA-GGA-AAA-AAT-ATG-GAA-AAT-AAC-AGC-CGCACT-ATG-CCC-CAT-ATA-AGG-CGG-ACA-ACT-CAT-ATT-ATGAAG-TTT-GCT-CAT-CGC-AAT-AGC-TTC-GAC-TTT-CAC-gCgTTC-AAT-GCC-CGT-TAG-TCT-ACC-GAC-TAA-GGG-CAC-TTCAGC-GTA-CAG-GTC-TTC-CTG-ACT-CTC-TGT-ATT-ACA-GGCATA-TGC-CTG-TAT-TCC-GCA-GTT-AAT-AAG-CAA-AAT-TCATTA-TAA-CC

TP_speFL_F31A CGA-TCG-AAT-TCT-AAT-ACG-ACT-CAC-TAT-AGG-GCT-TAAGTA-TAA-GGA-GGA-AAA-AAT-ATG-GAA-AAT-AAC-AGC-CGCACT-ATG-CCC-CAT-ATA-AGG-CGG-ACA-ACT-CAT-ATT-ATGAAG-TTT-GCT-CAT-CGC-AAT-AGC-TTC-GAC-TTT-CAC-TTCgCg-AAT-GCC-CGT-TAG-TCT-ACC-GAC-TAA-GGG-CAC-TTCAGC-GTA-CAG-GTC-TTC-CTG-ACT-CTC-TGT-ATT-ACA-GGCATA-TGC-CTG-TAT-TCC-GCA-GTT-AAT-AAG-CAA-AAT-TCATTA-TAA-CC

TP_speFL_N32A CGA-TCG-AAT-TCT-AAT-ACG-ACT-CAC-TAT-AGG-GCT-TAAGTA-TAA-GGA-GGA-AAA-AAT-ATG-GAA-AAT-AAC-AGC-CGC- 
bioRxiv preprint doi: https://doi.org/10.1101/604074: this version posted November 25,2019 . The copyright holder for this preprint (which was not certified by peer review) is the author/funder, who has granted bioRxiv a license to display the preprint in perpetuity. It is made available under aCC-BY-NC-ND 4.0 International license.

\begin{tabular}{ll}
\hline Name & Sequence \\
\hline ACT-ATG-CCC-CAT-ATA-AGG-CGG-ACA-ACT-CAT-ATT-ATG- \\
AAG-TTT-GCT-CAT-CGC-AAT-AGC-TTC-GAC-TTT-CAC-TTC- \\
TTC-gCg-GCC-CGT-TAG-TCT-ACC-GAC-TAA-GGG-CAC-TTC- \\
AGC-GTA-CAG-GTC-TTC-CTG-ACT-CTC-TGT-ATT-ACA-GGC- \\
ATA-TGC-CTG-TAT-TCC-GCA-GTT-AAT-AAG-CAA-AAT-TCA- \\
TTA-TAA-CC \\
\hline
\end{tabular}




\section{Supplementary Table 3 | Cryo-EM statistics and model refinement}

\begin{tabular}{|c|c|c|}
\hline & $\begin{array}{l}\text { \#1 SpeFL-ESRF } \\
\text { (EMDB-10458) } \\
\text { (PDB 6TC3) }\end{array}$ & $\begin{array}{l}\text { \#2 SpeFL-DLS } \\
\text { (EMDB-10453) } \\
\text { (PDB 6TBV) }\end{array}$ \\
\hline \multicolumn{3}{|l|}{$\begin{array}{l}\text { Data collection and } \\
\text { processing }\end{array}$} \\
\hline Magnification & $130,000 x$ & $130,000 x$ \\
\hline Voltage (kV) & 300 & 300 \\
\hline Electron exposure $\left(\mathrm{e}-/ \AA^{2}\right)$ & 30 & 29.6 \\
\hline Defocus range $(\mu \mathrm{m})$ & -0.5 to -1.6 & -0.6 to -1.5 \\
\hline Pixel size $(\AA)$ & 1.067 & 1.067 \\
\hline Symmetry imposed & $\mathrm{C} 1$ & $\mathrm{C} 1$ \\
\hline Initial particle images (no.) & 226,054 & 305,663 \\
\hline Final particle images (no.) & 68,195 & 137,494 \\
\hline Map resolution $(\AA)$ & 2.7 & 2.7 \\
\hline FSC threshold & 0.143 & 0.143 \\
\hline Map resolution range $(\AA)$ & $2.5-10$ & $2.5-8.7$ \\
\hline \multicolumn{3}{|l|}{ Refinement } \\
\hline $\begin{array}{l}\text { Initial model used (PDB } \\
\text { code) }\end{array}$ & $4 y b b$ & $4 y b b$ \\
\hline Model resolution $(\AA)$ & 2.1 & 2.1 \\
\hline FSC threshold & 0.143 & 0.143 \\
\hline Model resolution range $(\AA ̊)$ & $2.1-69.39$ & $2.1-69.39$ \\
\hline Map sharpening $B$ factor $\left(\AA^{2}\right)$ & -10 & -10 \\
\hline \multicolumn{3}{|l|}{ Model composition } \\
\hline Non-hydrogen atoms & 245,116 & 245,116 \\
\hline Protein residues & 10,310 & 10,310 \\
\hline & & \\
\hline \multicolumn{3}{|l|}{$B$ factors $\left(\AA^{2}\right)$} \\
\hline Protein & 48.22 & 53.05 \\
\hline Ligand & 34.32 & 38.14 \\
\hline \multicolumn{3}{|l|}{ R.m.s. deviations } \\
\hline Bond lengths ( $(\AA)$ & 0.01 & 0.01 \\
\hline Bond angles $\left({ }^{\circ}\right)$ & 0.97 & 0.93 \\
\hline \multicolumn{3}{|l|}{ Validation } \\
\hline MolProbity score & 1.21 & 1.17 \\
\hline Clashscore & 1.82 & 1.66 \\
\hline Poor rotamers $(\%)$ & 0.41 & 0.6 \\
\hline \multicolumn{3}{|l|}{ Ramachandran plot } \\
\hline Favored (\%) & 96.12 & 96.27 \\
\hline Allowed (\%) & 3.74 & 3.66 \\
\hline Disallowed (\%) & 0.14 & 0.07 \\
\hline
\end{tabular}


bioRxiv preprint doi: https://doi.org/10.1101/604074; this version posted November 25, 2019. The copyright holder for this preprint (which was not certified by peer review) is the author/funder, who has granted bioRxiv a license to display the preprint in perpetuity. It is made available under aCC-BY-NC-ND 4.0 International license.

\section{Supplementary Data 1}

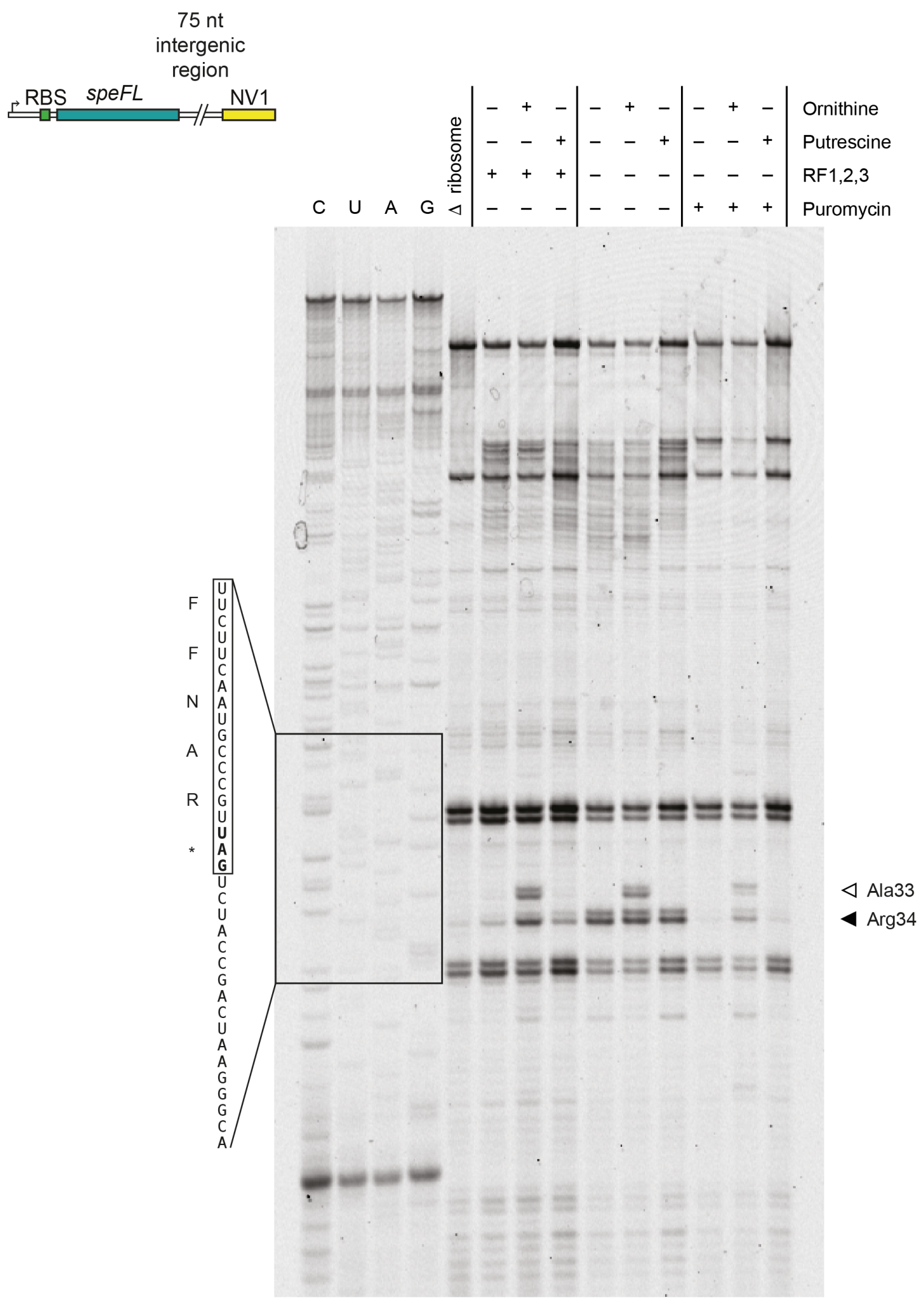


Supplementary Data 1 | Ornithine-dependent ribosomal stalling on speFL. Toeprinting assay $y^{3,4}$ to monitor the translation of speFL in the absence (-) or presence $(+)$ of $10 \mathrm{mM}$ ornithine, 10 $\mathrm{mM}$ putrescine, release factors $(\mathrm{RF} 1,2,3)$ or $90 \mu \mathrm{M}$ puromycin. Arrows indicate ribosomes stalled with the codon for the indicated amino acid in the P-site (Ala33 - open triangle; Arg34 filled triangle). A schematic representation of the DNA template used for toeprinting is provided (RBS - ribosome binding site; $N V 1^{5}$ - sequence used to anneal the Yakima Yellow-labeled probe for reverse transcription). 


\section{Supplementary Data 2}
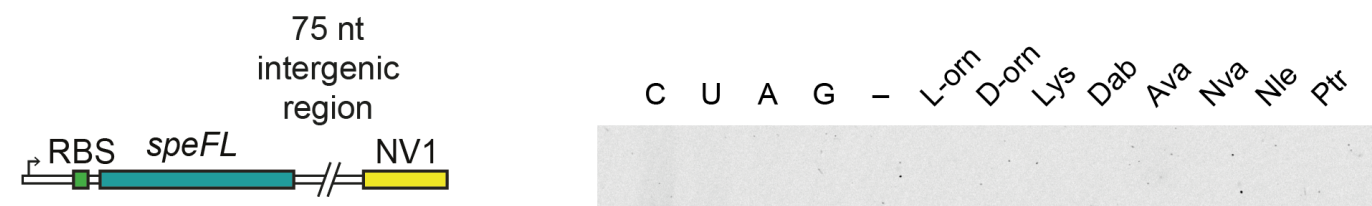

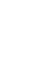
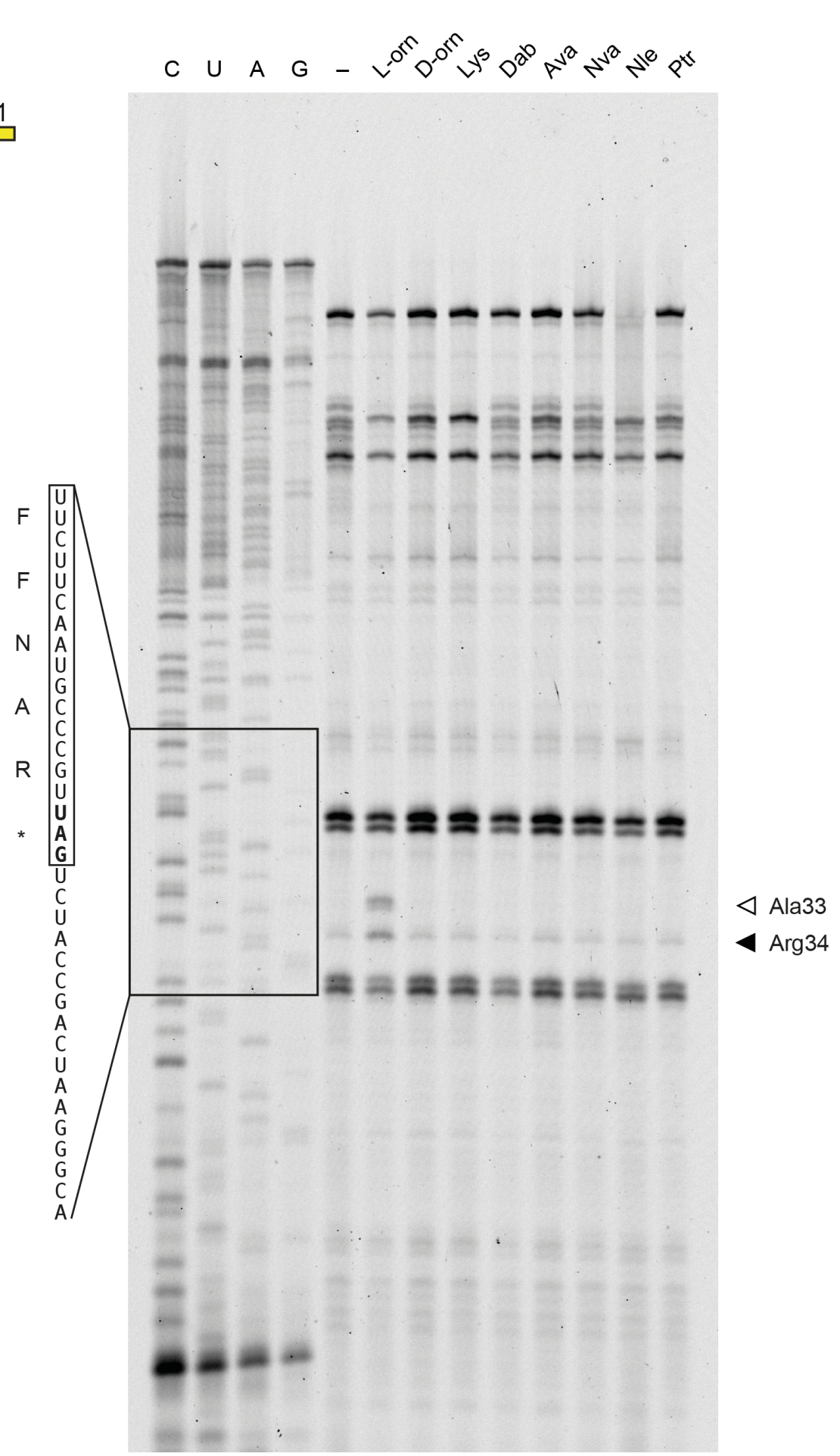

Supplementary Data 2 | Selectivity of SpeFL for L-ornithine. Toeprinting assay ${ }^{3,4}$ to monitor the translation of wild-type (WT) spe $F L$ in the absence $(-)$ or presence of $10 \mathrm{mM}(+)$ of various small molecules (see Fig. 2e for details). All samples were treated with $90 \mu \mathrm{M}$ puromycin. Arrows indicate ribosomes stalled with the indicated amino acid in the P-site (Ala33 - open triangle; Arg34 - filled triangle). A schematic representation of the DNA template used for toeprinting is provided (RBS - ribosome binding site; $N V 1^{5}$ - sequence used to anneal the Yakima Yellow-labeled probe for reverse transcription). 
bioRxiv preprint doi: https://doi.org/10.1101/604074; this version posted November 25, 2019. The copyright holder for this preprint (which was not certified by peer review) is the author/funder, who has granted bioRxiv a license to display the preprint in perpetuity. It is made available under aCC-BY-NC-ND 4.0 International license.

\section{Supplementary Data 3}
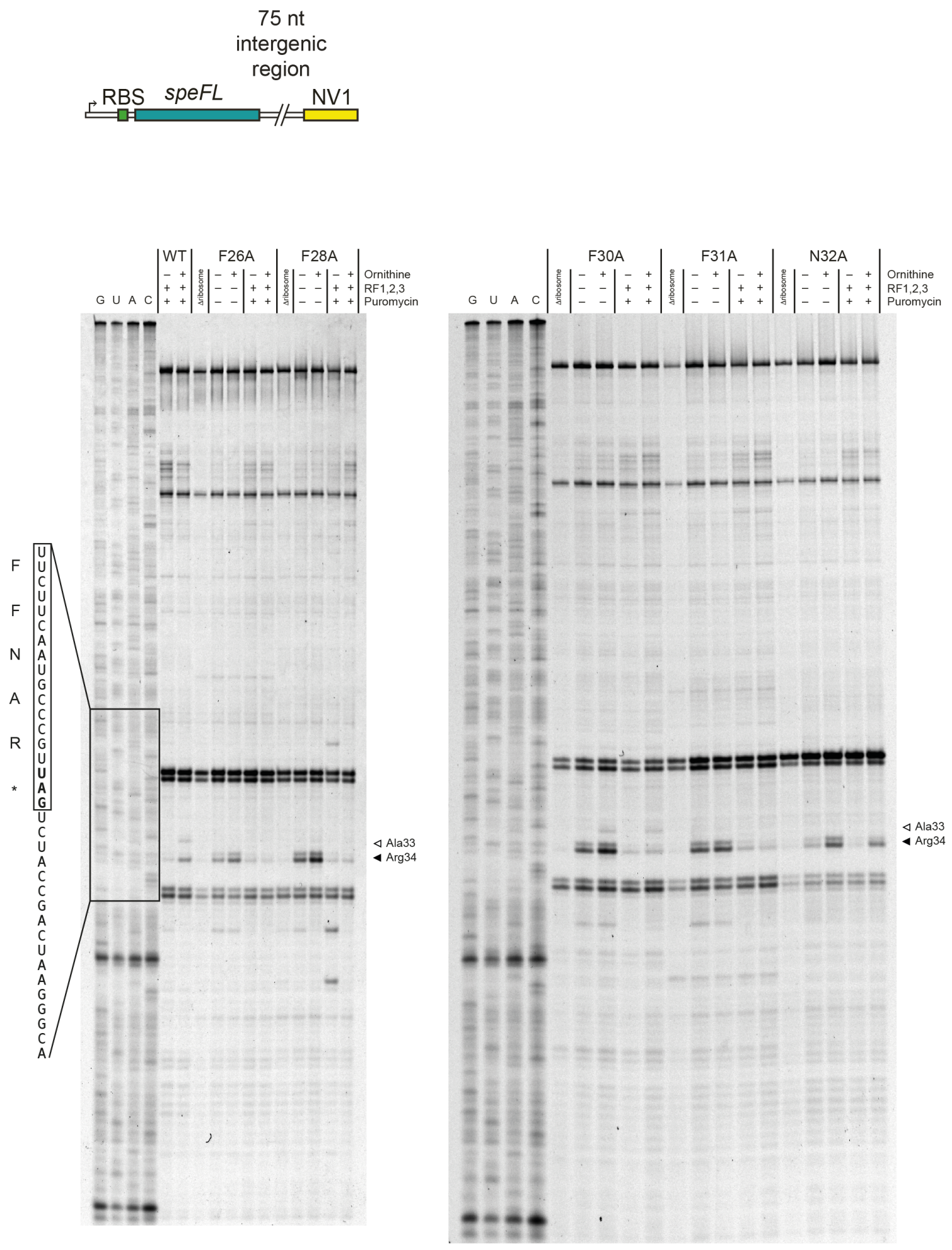

Supplementary Data 3 | Aromatic residues in the SpeFL effector domain are important for translational arrest. Toeprinting assay ${ }^{3,4}$ to monitor the translation of wild-type (WT) and mutant speFL in the absence (-) or presence $(+)$ of $10 \mathrm{mM}$ ornithine, release factors (RF1,2,3) or $90 \mu \mathrm{M}$ puromycin. Arrows indicate ribosomes stalled with the indicated amino acid in the Psite (Ala33 - open triangle; Arg34 - filled triangle). A schematic representation of the DNA 
bioRxiv preprint doi: https://doi.org/10.1101/604074; this version posted November 25, 2019. The copyright holder for this preprint (which was not certified by peer review) is the author/funder, who has granted bioRxiv a license to display the preprint in perpetuity. It is made available under aCC-BY-NC-ND 4.0 International license.

template used for toeprinting is provided (RBS - ribosome binding site; $N V 1^{5}$ - sequence used to anneal the Yakima Yellow-labeled probe for reverse transcription). 


\section{SUPPLEMENTARY REFERENCES}

1 Ben-Zvi, T. et al. mRNA dynamics and alternative conformations adopted under low and high arginine concentrations control polyamine biosynthesis in Salmonella. PLOS Genet 15, e1007646 (2019).

2 Bateman, A., Coggill, P. \& Finn, R. D. DUFs: families in search of function. Acta Crystallogr Sect F Struct Biol Cryst Commun 66, 1148-1152 (2010).

3 Hartz, D., McPheeters, D. S., Traut, R. \& Gold, L. Extension inhibition analysis of translation initiation complexes. Methods Enzymol 164, 419-425 (1988).

4 Seefeldt, A. C. et al. The proline-rich antimicrobial peptide Onc112 inhibits translation by blocking and destabilizing the initiation complex. Nat Struct Mol Biol 22, 470-475 (2015). Vazquez-Laslop, N., Thum, C. \& Mankin, A. S. Molecular mechanism of drugdependent ribosome stalling. Mol Cell 30, 190-202 (2008).

6 Di Salvo, M., Puccio, S., Peano, C., Lacour, S. \& Alifano, P. RhoTermPredict: an algorithm for predicting Rho-dependent transcription terminators based on Escherichia coli, Bacillus subtilis and Salmonella enterica databases. BMC Bioinformatics 20, 117 (2019). Scheres, S. H. RELION: implementation of a Bayesian approach to cryo-EM structure determination. J Struct Biol 180, 519-530 (2012).

8 Zivanov, J., Nakane, T. \& Scheres, S. H. W. A Bayesian approach to beam-induced motion correction in cryo-EM single-particle analysis. IUCrJ 6, 5-17 (2019).

9 Punjani, A., Rubinstein, J. L., Fleet, D. J. \& Brubaker, M. A. cryoSPARC: algorithms for rapid unsupervised cryo-EM structure determination. Nat Methods 14, 290-296 (2017).

10 Pettersen, E. F. et al. UCSF Chimera--a visualization system for exploratory research and analysis. J Comput Chem 25, 1605-1612 (2004).

11 Svidritskiy, E., Ling, C., Ermolenko, D. N. \& Korostelev, A. A. Blasticidin S inhibits translation by trapping deformed tRNA on the ribosome. Proc Natl Acad Sci U S A 110, 12283-12288 (2013).

12 Bulkley, D., Innis, C. A., Blaha, G. \& Steitz, T. A. Revisiting the structures of several antibiotics bound to the bacterial ribosome. Proc Natl Acad Sci U S A 107, 1715817163 (2010).

13 Dunkle, J. A., Xiong, L., Mankin, A. S. \& Cate, J. H. Structures of the Escherichia coli ribosome with antibiotics bound near the peptidyl transferase center explain spectra of drug action. Proc Natl Acad Sci U S A 107, 17152-17157 (2010).

14 Noeske, J. et al. Synergy of streptogramin antibiotics occurs independently of their effects on translation. Antimicrob Agents Chemother 58, 5269-5279 (2014).

15 Polikanov, Y. S. et al. Distinct tRNA Accommodation Intermediates Observed on the Ribosome with the Antibiotics Hygromycin A and A201A. Mol Cell 58, 832-844 (2015).

16 Wilson, D. N. et al. The oxazolidinone antibiotics perturb the ribosomal peptidyltransferase center and effect tRNA positioning. Proc Natl Acad Sci U S A 105, 1333913344 (2008).

17 Hansen, J. L., Schmeing, T. M., Moore, P. B. \& Steitz, T. A. Structural insights into peptide bond formation. Proc Natl Acad Sci U S A 99, 11670-11675 (2002).

18 Bashan, A. et al. Structural basis of the ribosomal machinery for peptide bond formation, translocation, and nascent chain progression. Mol Cell 11, 91-102 (2003).

19 Bischoff, L., Berninghausen, O. \& Beckmann, R. Molecular basis for the ribosome functioning as an L-tryptophan sensor. Cell Rep 9, 469-475 (2014). 